






ANNELIDES POLYCHETES 


\section{TABLE DES MATIERES}

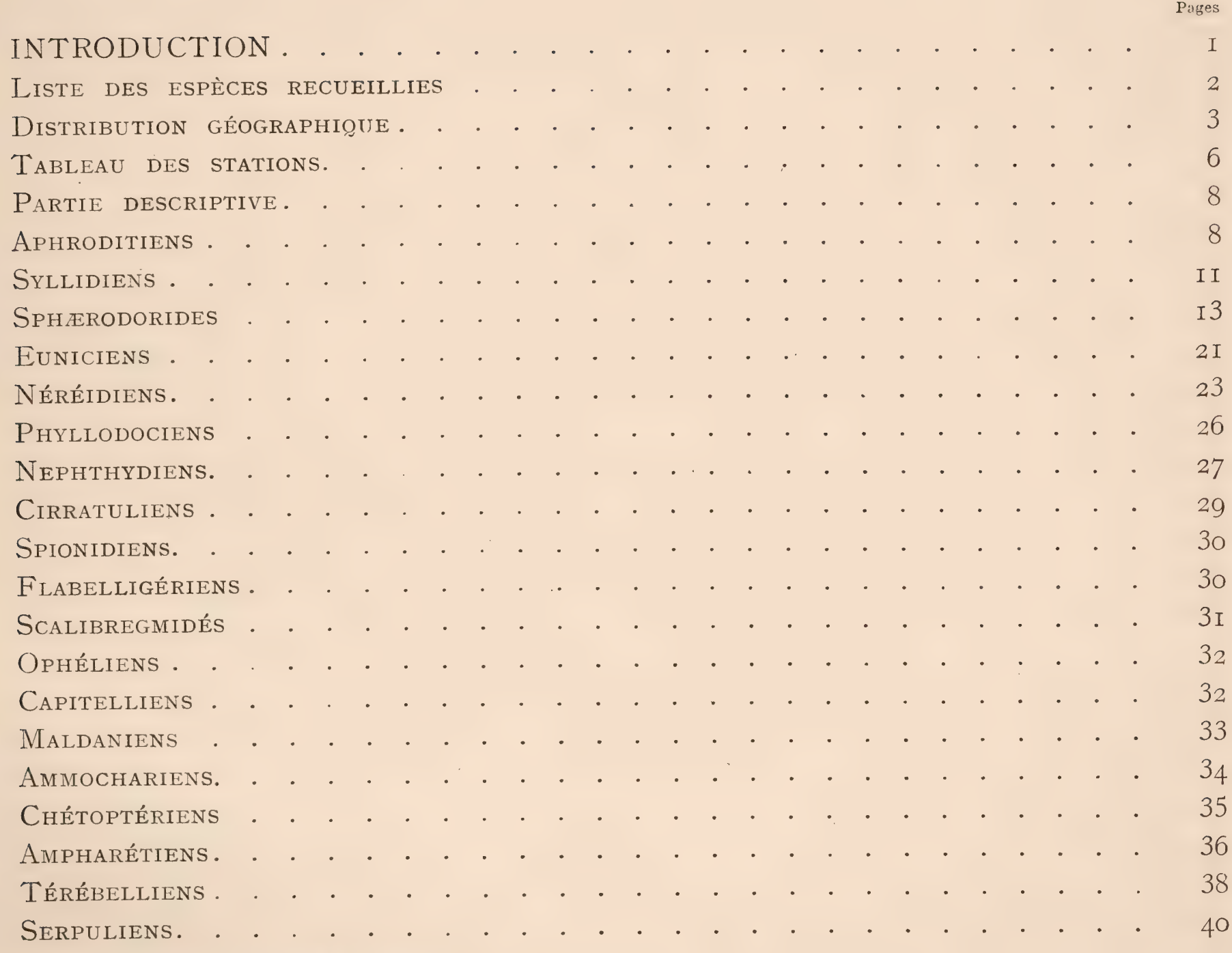

INDEX BIBLIOGRAPHIQUE.

EXPLICATION DE LA PLANCHE.

PLANCHE DES ANNÉLIDES. 


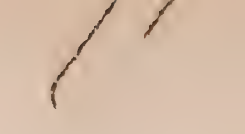




\title{
ANNÉLIDES POLYCHETTES
}

\author{
par Pierre FAUVEL \\ Professeur à l'Université catholique d'Angers
}

Pendant la campagne scientifique de Mgr LE Duc D'Orléans, à bord de la Belgica, en I907, M. le Dr Stappers recueillit, autour de la Nouvelle-Zemble et principalement dans la Mer de Kara et la Mer Mourmane, une collection d'Annélides dont il a bien voulu me confier la détermination. Cette étude fait l'objet du présent Mémoire.

Le nombre des espèces rapportées (cinquante-deux) est relativement élevé pour le petit nombre de stations (trente-six). Leur état de conservation fait honneur au soin avec lequel le matériel a été recueilli.

La faune des Annélides de la Nouvelle-Zemble ayant déjà fait l'objet des travaux d'Ehlers (i873), de Marenzeller (I877), de Théel (I879), de Levinsen (I886) est assez bien connue.

En 1879, ThÉEL en signalait cent deux espèces dont la plupart, comme le montre son tableau, appartiennent en même temps à la faune du Spitsbergen et du Grönland.

D'ailleurs, presque toutes les espèces boréales d'Annélides sont circumpolaires. La Mer du Grönland, la Mer de Barents, la Mer de Kara ont une faune identique, différant à peine de celle de la Mer de Behring, et s'étendant aux côtes de Norvège.

Beaucoup de ces espèces boréales se trouvent dans la Mer du Nord, la Manche, l'Atlantique jusqu'aux Açores et aux Canaries et même pénètrent dans la Méditerranée.

Un certain nombre existent au Japon et descendent dans le Pacifique le long des côtes de l'Amérique du Nord ou gagnent l'Océan Indien en suivant les côtes asiatiques (FAUVEL, IgII $\left.{ }^{\mathrm{D}}\right)$. 
Depuis Linné la faune des côtes de Norvège a donné lieu à de nombreux travaux; d'autre part, les expéditions polaires ont été très multipliées et leurs abondants matériaux ont presque toujours été soigneusement étudiés. Il en résulte que l'on peut soutenir sans exagération que la faune des Annélides boréales est bien mieux connue que celle des côtes de France.

Il ne fallait donc pas s'attendre à trouver beaucoup de nouveautés dans le matériel recueilli par la Belgica. La liste suivante des espèces rapportées par cette expédition ne contient, en effet, qu'une seule espèce nouvelle, le Spharodorum Philippi.

Les espèces non encore signalées sur les côtes de la Nouvelle-Zemble sont marquées d'une astérisque. Toutes les autres ont déjà été mentionnées par THÉEL et Levinsen.

\section{ANNÉLIDES POLYCHÈTES}

Aphroditiens

Eunoë nodosa Sars.

Lagisca rarispina Malmgren.

Antinoë Sarsi Malmgren.

Pholoë minuta Fabricius.

Syllidiens

Syllis Erstedi Malmgren.

Syllis fasciata Malmgren.

* Eusyllis Blomstrandi Malmgren.

* Autolytus prolifer Malmgren.

Autolytus longisetosus Ersted.

SPHeRODORIDES

Ephesia gracilis Rathke.

* Ephesia peripatus Claparède.

* Spharodorum Philippi n. sp.

\section{Euniciens}

Omuphis conchylega Sars.

Lumbriconereis fragilis Müller.

Lumbriconereis mimuta Théel.

Neréidiens

Nereis zonata Malmgren.

\section{Phyllodociens}

Phyllodoce groenlandica Ersted. Anaitis Wahlbergi Malmgren.

Eteone depressa Malmgren.

\section{NePHTHYDIENS}

Nephthys ciliata Müller.

Nephthy's paradoxa Malm.

Nephthys Malmgreni Théel.

\section{Cirratuliens}

Cheitozone setosa Malmgren.

Spionidiens

Aonides cirrata Sars.

\section{Flabelligériens}

Flabelligera affinis Sars.

Stylarioïdes plumosa O. F. Müller.

\section{SCALIBREgMidÉS}

Pseudoscalibregma longisetosum Théel.

\section{OphéLIENS}

Ammotrypane cylindricaudatus Hansen. 


\section{Capitelliens}

Notomastus latericeus Sars.

\section{Maldaniens}

Maldane Sarsi Malmgren.

* Praxillura longissima Arwidsson.

\section{AMMOCHARIENS}

Owenia assimilis Sars.

Myriochele Heeri Malmgren.

Chétoptériens

Spiochatopterus typicus Sars.

\section{Ampharétiens}

* Amphicteis Sundevalli Malmgren. Ampharete arctica Malmgren.

Ampharete gracilis Malmgren.

* Samytha sexcirrata Sars.

Melinna cristata Sars.

\section{TÉRÉBELLIENS}

Amphitrite cirrata Müller. Scione lobata Malmgren.

Thelepus cincinnatus Fabricius.

Polycirrus albicans Malmgren.

\author{
Serpuliens \\ * Potamilla neglecta Sars. \\ Dasychone infarcta Kröyer. \\ * Dasychone Bombyx Dalyell. \\ Chone infundibuliformis Kröyer. \\ Chone Dineri Malmgren. \\ Euchone analis Kröyer. \\ Euchone papillosa Sars. \\ Chitinopoma Fabricii Levinsen. \\ Apomatus similis Mar. (=A.globiter Théel).
}

Ces cinquante-deux espèces se répartissent en dix-neuf familles dont les mieux représentées sont : les Serpuliens (neuf espèces), les Ampharétiens et les Syllidiens (cinq espèces), les Aphroditiens et les Térébelliens (quatre espèces).

La petite famille des Sphærodoridés, dont les espèces sont si peu nombreuses, en fournit trois, dont une de chaque section.

En dehors du Spharodorum Philippi, espèce entièrement nouvelle, les espèces non encore signalées dans les parages de la Nouvelle-Zemble sont les huit suivantes :

Eusyllis Blomstrandi, Autolytus prolifer, Ephesia peripatus, Praxillura longissima, Amphicteis Sundevalli, Samytha sexcirrata, Potamilla neglecta et Dasychone Bombyx.

L'Eusyllis Blomstrandi, l'Amphicteis Sundevalli, la Samytha sexcirrata, la Potamilla neglecta existent au Spitsbergen; l'Autolytus prolifer, au Grönland et en Norvège; la Praxillura longissima à Jan Mayen et en Norvège; l'Ephesia peripatus (Spharodorum abyssorum Hansen) et le Dasychone Bombyx ( $D$. Dalyelli Mgr.) vivent également au large de la Norvège.

Examinons maintenant la provenance des espèces de la Belgica.

L'Océan Glacial arctique a fourni sept espèces :

Lumbriconereis fragilis.

Maldane Sarsi.

Owenia assimilis.

Spiochatopterus typicus.
Ampharete arctica.

Samytha sexcirrata.

Chone Duneri. 
La Mer de Barents a donné, entre la Nouvelle-Zemble et la Norvège, Maldane Sarsi et Spiochatopterus typicus, puis sur la côte ouest de l'lle Sud de la NouvelleZemble, l'Autolytus longisetosus et la Nereis zonata.

Dans le Matotchkine Char on n'a recueilli que la Phyllodoce groenlandica.

La Mer de Kara, la Porte de Kara et la Mer Mourmane, sur la côte sud de la Nouvelle-Zemble, ont fourni, de beaucoup; les récoltes les plus riches :

Mer de Kara, côte est de l'Ile Sud de la Nouvelle-Zemble (stations 24 à I39), seize espèces :

Eunö̈ nodosa.

Antinoë Sarsi.

Syllis Erstedi.

Autolytus prolifer.

Autolytus longisetosus.

Spharodorum Philippi.

Omphis conchylega.

Nereis zonata.
Nephthys Malmgreni.

Pseudoscalibregma longisetosum.

Myriochele Heeri.

Spiochatopterus typicus.

Thelepus cincimnatus.

Dasychone infarcta.

Clone infundibuliformis.

Apomatus similis.

Porte de Kara (stations 142 à I43), vingt-neuf espèces :

Eunö̈ nodosa.

Lagisca rarispina.

Pholö mimuta.

Syllis fasciata.

Eusyllis Blomstrandi.

Autolytus prolifer.

Ephesia gracilis.

Flabelligera affinis.

Stylarioüdes plumosa.

Ammotrypane cylindricaudatus.

Notomastus latericeus.

Praxillura longissima.

Myriochele Heeri.

Ampharete arctica.
Ephesia peripatus.

Omphis conchylega.

Nereis zonata.

Phyllodoce groenlandica.

Anaitis Wahlbergi.

Nephthys ciliata.

Nephthys paradoxa.

Melinna cristata.

Scione lobata.

Thelepus cincimatus.

Polycirrus albicaus.

Dasychone infarcta.

Chone infundibuliformis.

Euchone analis.

Chitinopoma Fabricii. 
Mer Mourmane, côte sud de la Nouvelle-Zemble (stations I54 à I63), vingt-neuf espèces :

Eunoë nodosa.

Lagisca rarispina.

Antinoë Sarsi.

Pholoë minuta.

Syllis fasciata.

Ephesia gracilis.

Omiphis conchylega.

Lumbriconereis minuta.

Nereis zonata.

Ampharete arctica.

Ampharete gracilis.

Amphitrite cirrata.

Scione lobata.

Thelepus cincinnatus.

Potamilla neglecta.
Phyllodoce groenlandica.

Eteone depressa.

Chceiozone setosa.

Aonides cirrata.

Flabelligera affinis.

Stylariö̈des plumosa.

Maldane Sarsi.

Spiochatopterus typicus.

* Amphicteis Sundralli.

Dasychone infarcta.

Dasychone Bombyx.

Chone infundibuliformis.

Euchone analis.

Euchone papillosa.

Les espèces qui ont été rencontrées le plus fréquemment sont : Nephthys Malmgreni, Onuphis conchylega, Nereis zonata, Ephesia gracilis, Spiochatopterus. typicus, Scione lobata, Thelepus cincinnatus, Dasychone infarcta, Chone infundibuliformis et Apomatus similis (=A. globifer $)$.

La Scione lobata est, de beaucoup, celle qui a été récoltée en plus grande quantité. Les tubes de cette espèce remplissaient cinq grands bocaux de plus d'un litre.

Le tableau suivant indique exactement la répartition par stations de toutes les espèces recueillies. 


\begin{tabular}{|c|c|c|c|c|c|c|}
\hline 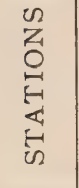 & DATES & LOCALITÉ & Lat. $N$ & LONG. E & 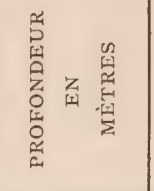 & $\begin{array}{c}\text { P R O CÉ D É } \\
\text { DE } \\
\text { RÉCOLTE }\end{array}$ \\
\hline 8 & $\begin{array}{c}1907 \\
\text { I } 2 \text { juillet }\end{array}$ & Mer de Barents & $72^{\circ} 5 o^{\prime}$ & $52^{\circ} 20^{\prime}$ & Surface & $\begin{array}{l}\text { Filet de surface } \\
\text { (soie 20). }\end{array}$ \\
\hline $24^{a}$ & I6 " & Mer de Kara & $72^{\circ} 48^{\prime}$ & $56^{\circ} \mathrm{I} 8^{\prime}$ & Surface & $\begin{array}{l}\text { Filet de surface et filet } \\
\text { de Damas. }\end{array}$ \\
\hline 27 & I6 " & Mer de Kara & $72^{\circ} 42^{\prime}$ & $56^{\circ} \mathrm{I} 7^{\prime}$ & Surface & Filet de Damas. \\
\hline 50 & 2311 & Mer de Kara & $71^{0} 58^{\prime}$ & $55^{\circ} 49^{\prime}$ & $105-75$ & Grand filet de Nansen. \\
\hline 62 & 27 & Mer de Kara & $71^{0} 49^{\prime}$ & $55^{\circ} 52^{\prime}$ & I 23 & Sondeur Gilson. \\
\hline 67 & 27 & Mer de Kara & $7^{1^{\circ}} 49^{\prime}$ & $55^{\circ} 52^{\prime}$ & $\mathrm{I} 23$ & Drague et 2 fauberts. \\
\hline 78 & $30 \quad 11$ & Mer de Kara & $71^{\circ} 42^{\prime}$ & $56^{\circ} 58^{\prime}$ & 2 & 3 fauberts sur barre. \\
\hline 79 & $3 I " 1$ & Mer de Kara & $71^{\circ} 39^{\prime}$ & $56^{\circ} \mathrm{O} 2^{\prime}$ & I 34 & 3 fauberts sur barre. \\
\hline I03 & 7 août & Mer de Kara & $71^{\circ} 32^{\prime}$ & $57^{\circ} \mathrm{IO}^{\prime}$ & $220-0$ & Grand filet de Nansen. \\
\hline I IO & $n$ & Mer de Kara & $7 \mathrm{I}^{\circ} 3 \mathrm{I}^{\prime}$ & $57^{\circ} \mathrm{og}^{\prime}$ & 220 & 3 fauberts sur barre. \\
\hline I I I & $"$ & Mer de Kara & $7 \mathrm{I}^{\circ} 3 \mathrm{I}^{\prime}$ & $57^{\circ} \circ 8^{\prime}$ & 220 & 3 fauberts sur barre. \\
\hline I I 2 & 8 & Mer de Kara & $71^{0} 26^{\prime}$ & $56^{\circ} 5 g^{\prime}$ & $200-150$ & Grand filet de Nansen. \\
\hline II 3 & 8 & Mer de Kara & $71^{0} 26^{\prime}$ & $56059^{\prime}$ & $200-0$ & Grand filet de Nansen. \\
\hline I I 5 & 8 & Mer de Kara & $71^{\circ} 26^{\prime}$ & $56^{\circ} 5 g^{\prime}$ & 200 & 3 fauberts sur barre. \\
\hline I I9 & 10 & Mer de Kara & $71^{0} 22^{\prime}$ & $566^{\circ} 57^{\prime}$ & I66 & 3 fauberts sur barre. \\
\hline $\mathrm{I} 2 \mathrm{O}$ & IO & Mer de Kara & $7 \mathrm{I}^{0} 2 \mathrm{I}^{\prime}$ & $56^{\circ} 57^{\prime}$ & I 65 & 3 fauberts sur barre. \\
\hline I 26 & II & Mer de Kara & $7 \mathrm{I}^{0} \mathrm{I} 8^{\prime}$ & $57^{\circ} 03^{\prime}$ & I 72 & 3 fauberts sur barre. \\
\hline I3o & I 2 & Mer de Kara & $71^{\circ} 08^{\prime}$ & $57^{0} 25^{\prime}$ & 205 & 3 fauberts sur barre. \\
\hline I34 & I3 & Mer de Kara & $7 \mathrm{I}^{\circ} \mathrm{O} 2^{\prime}$ & $57^{\circ} 50^{\prime}$ & 210 & 3 fauberts sur barre. \\
\hline I 35 & 13 & Mer de Kara & $7^{1^{\circ}} \mathrm{O}^{\prime}$ & $57^{0} 55^{\prime}$ & 212 & $\begin{array}{l}\text { Filet de fond (en éta- } \\
\text { mine). }\end{array}$ \\
\hline I 36 & 14 & Mer de Kara & $7 \mathrm{I}^{\circ} \mathrm{OI}^{\prime}$ & $57^{\circ} 57^{\prime}$ & 216 & $\begin{array}{l}\text { Filet de fond (en éta- } \\
\text { mine). }\end{array}$ \\
\hline I 38 & I4 " & Mer de Kara & $70^{\circ} 58^{\prime}$ & $58^{\circ} \mathrm{O} 4^{\prime}$ & $2 \mathrm{I} 2$ & $\begin{array}{l}\text { Filet de fond (en éta- } \\
\text { mine). }\end{array}$ \\
\hline 139 & I $5 \%$ & Mer de Kara & $70^{\circ} 54^{\prime}$ & $58^{\circ} 28^{\prime}$ & 200 & $\begin{array}{l}\text { Drague rectangulaire } \\
\text { garnie de } 3 \text { fauberts. }\end{array}$ \\
\hline 142 & I6 & Porte de Kara & $70^{\circ} 38^{\prime}$ & $58030^{\prime}$ & I $20-30$ & Grand filet de Nansen. \\
\hline 146 & I6 " & Porte de Kara & $70^{\circ} 40^{\prime}$ & $58^{\circ} 33^{\prime}$ & I 35 & 3 fauberts sur barre. \\
\hline
\end{tabular}

ANNÉLIDES RECUEILLIES

Syllis Erstedi Malmgren.

Syllis Erstedi Mgr.

Autolytus prolifer Müll

Spiochatopterus typicus Sars.

Neplithys Malmgreni Théel.

Spiochatopterus typicus Sars. - Apamatus similis Mar. Bobr.

Onuphis conchylega Sars.

Antinoë Sarsi Mgr. - Spharodorum Philippi n. spec.

Antinoë Sırsi Mgr. - Aponatus similis Mar. Bobr.

Apomatus similis Mar. Bobr.

Antinoë Sarsi Mgr.

Nephthys Malmgreni Théel.

Spiochatopterus typicus Sars. - Dasychone infarcta Kröyer. - Chone infundibuliformis Kröyer.Apomatus similis Mar. Bobr.

Chone infundibuliformis Kr. - Apomatus similis Mar. Bobr.

Apomatus similis Mar. Bobr.

Apomatus similis Mar. Bobr.

Eunoc̈ nodosa Sars.

Nereis zonata $\mathrm{Mgr}$.

Omphis conchylega Sars. - Nephthy's Mahmgreni Théel.

Nephthys Malmgreni Théel - Pseudoscalibregma longisetosum Théel.

Nephthys Malmgreni Théel. - Myriochele Hoeri Mgr. - Thelepus cincinnatus Fabr. - Dasy chone infarcta Kröyer.

Spiochoctopterus typicus Sars.

Pholoë minuta Fabr. - Ephesia gracilis Rathke.

Eunö̈ nodosa Sars. - Onuphis conchylega Sars. - Nephthys ciliata Müll. - Stylarioides plumosa Müll. - Notomastus latericeus Sars. Praxillura longissima Arw. - Myriochele Heer Mgr. - Melinna cristata Sars. - Thelepu cincinnatus Fabr. - Dasychone spec. - Chon infundibuliformis Kröyer. 


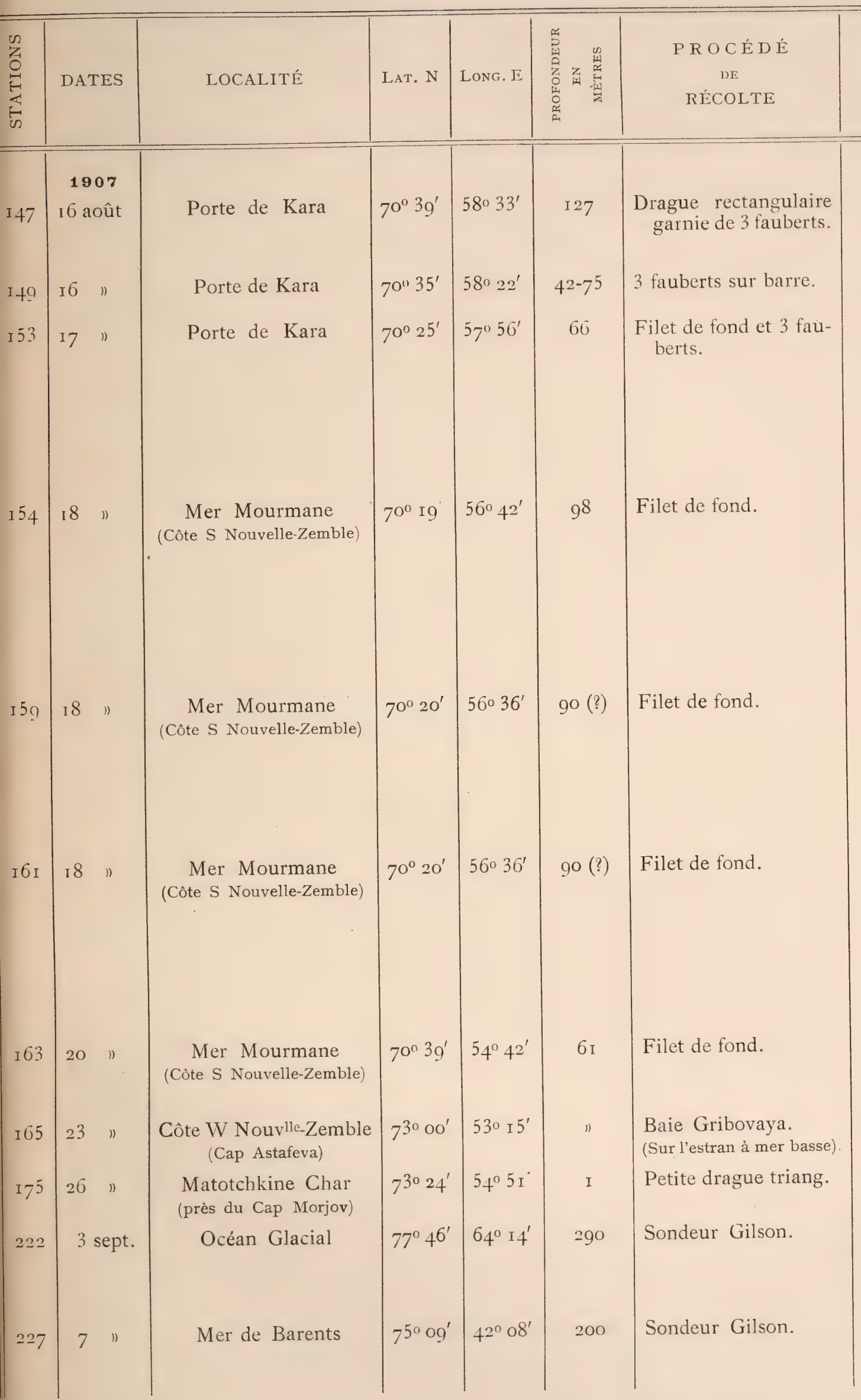

ANNÉLIDES RECUEILLIES

Phyllodoce groenlandica CErst. - Nephthys paradoxa Malm. - Ephesia gracilis Rathke. Ephesia peripatus Clap. - Thelepus cincinnatus Fabr. - Chone infundibuliformis Kröyer.

Ephesia gracilis Rathke. - Thelepus cincinnatus Fabr. - Chone infundibuliformis Kröyer.

Eunoë nodosa Sars. - Lagisca rarispina Mgr. Syllis fasciata Mgr. - Eusyllis Blomstrandi Mgr. - Autolytus prolifer Müll. - Anaïtis Wahlbergi Mgr. - Ephesia gracilis Rathke.-Flabelligera affinis Sars. - Ammotrypane cylindricaudatus Hansen. - Scione lobata Mgr. - Thelepus cincinnatus Fabr. - Polycirrus albicaus Mgr. - Dasychone infarcta Kröyer - Chone infundi. buliformis Kröyer. - Euchone analis Kröyer. - Chitinopoma Fabricii Levinsen.

Eunoë nodosa Sars. - Syllis fasciata Mgr. Lumbriconereis minuta Théel. - Nereis zonata Mgr. - Eplesia gracilis Rathke. - Aonides cirrata Sars. - Flabelligera affinis Sars cirrata Sars. - Flabelligera affinis Sars Stylarioides plunosa Mull. - Mpiochatopteris typicus Sars. Mgr. - Spiochatopterns typicus Sars. Ampharete arctica Mgr. - Ampharete gracilis cinnatus Fabr. - Dasychone infarcta Kröyer. - Dasychone Bombyx Dall. - Chone infundibuliformis Kröyer.

Lagisca rarispina Mgr. - Syllis fasciata Mgr. Onuphis conchylega Sars. - Nereis zonata Mgr. - Euchone depressa Mor. - Ephesia gracilis Rathke. - Chatozone setosa Mgr. - Stylaviö̈des plumosa Müll. - Spiochatopterus typicus Sars. Ampharete arctica Mor. - Scion Sars. - Anpharetele cincinzatus Fabr Dasychome infarcta Kröyer. Chone infundiDasychone infarcta Kroyer. - Chone Küner.

Lagisca rarispina Mgr. - Pholoë minuta Fabr. Syllis fasciata Mgr. - Onuphis conchylega Sars. - Nereis zonata Mgr. - Ephesia gracilis Rathke. - Spiochcetopterus typicus Sars. cilis Rathke, - Spiochal Prn. - Amphitrite - Amphicteis Sundevalli Mgr. - Amphitrite cirrata Müll. - Scione lobata Mgr. - Thelepus cincinnatus Fabr. - Potamilla neglecta Sars - Dasychone infarcta Kröyer. - Dasychone spec. - Chone infund

Lagisca rarispina Mgr. - Antinoë Sarsi Mgr. - Pholoë minuta Fabr. - Phyllodoce groenlandica Erst. - Flabelligeva affinis Sars. Scione lobata Mgr.

Nereis zonata Mgr. épitoke 오.

Phyllodoce groenlandica Erst.

Lumbriconereis fragilis Müll. - Maldane Sarsi Mgr. - Owenia assimilis Sars. - Spiochoetop. terus typicus Sars. - Ampharete arctica Mor. - Samutha sexcirrata Sars. - Chone Duneri Mor. Maldane Sarsi Mgr. - Spiochatopterus typicus Sars. 


\section{Famille des Aphroditiens Savigny}

\section{Genre Eunoë Malmgren}

\section{Eunoë nodosa Sars (I).}

Polynoë nodosa Sars (I860), p. 5 q.

Eunoë nodosa Sars Malmaren (I865); p. 64, pl. VIII, fig. 4.

Lepidonote scabra (ERSTED (I843), pp. I64-I66 (nec FabRicIÚs).

Eunoë arstedi Malmgren (I865), p. 6I, pl. VIII, fig. 3.

Polynoë scabra Théel (I879), p. 7.

Eunoë scabra Marenzeller (I886), p. II

Eunoa nodosa Mc'Intosh (Igoo), p. 292.

Harmothoë nodosa Levinsen (i883), p. I93.

\section{Matériel Recueilli :}

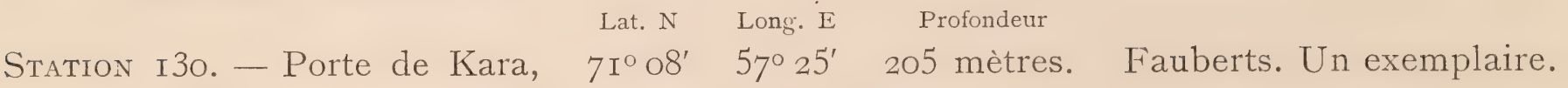

Station I46. - Porte de Kara, $70^{\circ} 40^{\prime}$ 580 33' i 35 mètres. Fauberts. Un exemplaire.

Station i53. - Porte de Kara, $70^{\circ} 25^{\prime} \quad 57^{\circ} 56^{\prime} \quad 66$ mètres. Filet de fond et fauberts.

Un exemplaire.

Station i54. - Mer Mourmane, $70^{\circ} 19^{\prime} \quad 56^{\circ} 42^{\prime} \quad 98$ mètres. Filet de fond. Un exempl.

Le petit spécimen de la station I30, tronqué postérieurement, est de la forme nodosa, à élytres fortement ciliés à nodosités peu nombreuses et pâles. Celui de la station I46, à corps court et ovale, mesurant 40 millimètres sur I7 millimètres, a aussi les élytres fortement ciliés à tubercules gros, peu nombreux, faiblement épineux. Il y a peu de différence de longueur entre les soies dorsales et les soies ventrales, mais les premières paraissent bien plus courtes étant insérées en retrait, elles sont notablement plus grosses que les inférieures.

Les spécimens des stations I53 et I54 sont plutôt de la forme Erstedi par les nodosités épineuses de leurs élytres, mais ceux-ci sont ciliés comme dans la forme nodosa, malgré leur grande taille.

(i) Pour ne pas développer outre mesure la bibliographie, je me borne à citer les synonymes avec l'indication de leurs autcurs ou de ceux qui en ont donné une description détaillée et des figures. 
Celui de la station I53, mesurant 60 millimètres sur I9 millimètres, soies comprises, porte des élytres régénérés aux troisième et quatrième sétigères de gauche. L'élytre du troisième sétigère mesure seulement 2 millimètres dans son grand axe. Celui du quatrième sétigère, encore plus petit, ne mesure que I.2 millimètre et dépasse à peine le diamètre de son pédoncule. Michel (IgII) a montré avec quelle rapidité les élytres peuvent se régénérer chez les Aphroditiens. Chez l'Halosydna gelatinosa, par exemple, au bout de deux jours, l'élytre régénéré atteint déjà la moitié du diamètre normal.

Le grand spécimen de la station 154 (73 millimètres sur 25 millimètres) a le premier élytre de gauche régénéré, blanchâtre, moitié plus petit que celui de droite. Les élytres et les soies sont couverts de Loxosomes.

C'est avec raison que Théel a réuni les deux espèces de Malmgren : E. nodosa et E. Erstedi, car la plupart des spécimens présentent à la fois les caractères prétendus distinctifs, et on trouve toutes les formes de passage entre les deux types extrêmes.

Théel a adopté le nom de Polynö̈ scabra, qui me paraît contestable. Le Lepidonote scabra d'ERsted me parait bien être l'espèce décrite plus tard par Malmaren sous le nom d'Eunoë Erstedi, mais. MaLmGRen a eu raison de rejeter le nom de scabra déjà employé pour désigner une autre espèce.

L'Aphrodite scabra de Fabricius et de Savigny, la Polynoe scabra d'Audouin et de Milne-Edwards paraissent être identiques à l'Aphrodita cirrhosa de Pallas, désignée maintenant sous le nom de Nychia ou Gattyana cirrosa.

D'autre part, l'Eunoë CErstedi Malmgren (Lepidonote scabra CErsted) n'étant qu'une forme de l'Eunö̈ nodosa, espèce bien connue et bien décrite, ce dernier nom, qui a la priorité, doit subsister.

Mc'Intosh (I9oo, p. 295) s'exprime ainsi. à ce sujet : "Théel (I879) noted that Eunoa nodosa and E. Erstedi Malmgren were the same species, viz. the Lepidonotus scabra of Ersted an opinion coïnciding with the remarks made by myself many years previously, " et cependant, chose étrange, dans sa bibliographie d'Eunoa nodosa, il n'indique ni Lepidonotus scabra Ersted, ni Eunoë. Erstedi Malmgren comme synonymes. Par contre, page 285, il indique Lepidonotus scabra Ersted comme synonyme de Gattyana cirrosa, au même titre que l'Aphrodita scabra Fabricius.

\section{Genre Lagisca Malmgren}

\section{Lagisca rarispina Malmgren (I865).}

Polynoë rarispina Théel (1879), p. 8.

? Lagisca propinqua MaLmaken (I867), p. I33, pl. II, fig. 3.

? Lagisca extenuata Grube (I840), p. 86. 


\section{Matériel RECUEILli :}

Lat. $\mathrm{N}$ Long. E Profondeur

Station 153. - Porte de Kara, $70^{\circ} 25^{\prime} 57^{\circ} 56^{\prime} 66$ mètres.

Station i59. - Mer Mourmane, $70^{\circ} 20^{\prime} \quad 56^{\circ} 36^{\prime} 90$ mèt. (?)

Station i6i. - Mer Mourmane, $70^{\circ} 20^{\prime} \quad 56^{\circ} 36^{\prime}$ go mèt. (?)

Station i63. - Mer Mourmane, $70^{\circ} 39^{\prime} 54^{\circ}$ I2 $2^{\prime} 6$ I mètres.
Filet de fond, fauberts.

Plusieurs exemplaires.

Filet de fond. Un exempl. Filet de fond. Deux ex.

Les exemplaires de la station I53 sont très nombreux, mais beaucoup sont cassés et ont perdu plus ou moins complètement leurs appendices et leurs élytres. Un petit spécimen, malheureusement incomplet, de la station I63, présente des caractères intermédiaires entre la Lagisca propinqua et la Lagisca rarispina. Les cirres tentaculaires portent deux soies, comme d'ailleurs chez la plupart des Lagisca. Quelques-unes seulement des soies ventrales supérieures sont bidentées, les autres sont à pointe lisse. Les papilles des élytres sont semblables à celles de $L$. propinqua, mais il n'y en a pas de globuleuses.

DE SAINT-Joseph (I898, p. 238) considère les $L$. propinqua et $L$. varispina comme de simples variétés de Lagisca extenuata; MC'InTosh, au contraire, considère ces espèces comme bien distinctes. Faute de matériel suffisant, je n'ose trancher la question, mais j'inclinerais plutôt vers l'opinion de DE SAInt-Joseph.

\section{Genre Antinoë Kinberg}

\section{Antinoё Sarsi (Kbg.) Malmgren.}

Antinoë Sarsi Malmgren (1865), p. 75, pl. IX, fig. 6 .

Polynoë Sarsi Théel (I879), F. I6.

Matériel RECUEILli :

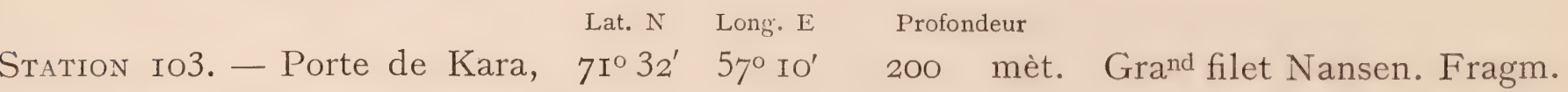
Station ilo. - Mer de Kara, $7 \mathrm{I}^{\circ} 3 \mathrm{I}^{\prime} 57^{\circ} 09^{\prime} 220$ mèt. Fauberts. Un exemplaire. Station II2. - Mer de Kara, 7 I $^{\circ} 26^{\prime}$ 56 59' 200-I5o mèt. Grand filet Nansen. Un ex.

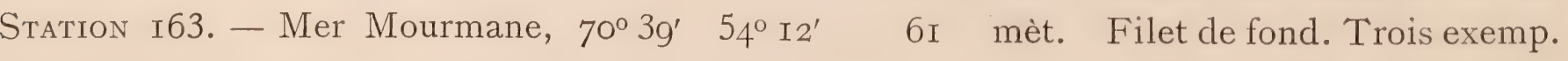

La plupart des spécimens sont de petite taille, 8 à I2 millimètres de long sur 3 à 4 millimètres. Ceux des stations Io3 et II 2 n'ont même que 2 millimètres.

Les élytres, à peine teintés du brun sur un tiers de leur surface, sont au nombre de douze, treize ou quinze paires. Le lobe céphalique est divisé en deux par un sillon longitudinal. Ces spécimens correspondent à la forme jeune décrite par Théél. 


\section{Genre Pholoë Johnston}

\section{Pholoë minuta Fabricius.}

Aphrodita minuta Fabricius (I780), pp. 3i4-3i5.

Pholoë minuta (Ersted (18433), p. I69, pl. I, fig. 3, 4, 8, 9, I6.

Pholoë baltica (ERsted (18435), p. I4, fig. 2I, 34-36, 40.

Pholoë assimilis Ersted (I844), p. 404, (fide Mc'Intosh).

Pholoë inornata Johnston (I865), p. I21, pl. V, fig. I-5.

Pholoë minuta Malmgren (i865), p. 89, pl. XI, fig. i 3 .

Pholoë minuta Mc'Intosh (I9oo), p. 437.

Matériel Recueilli :

Lat. $N$ Long. $\mathrm{E} \quad$ Profondeur

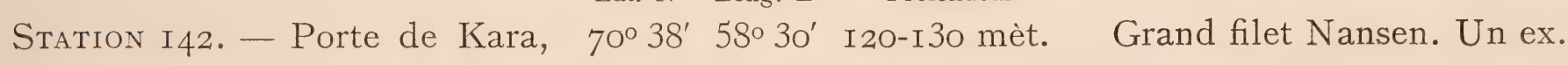
Station i6i. - Mer Mourmane, $70^{\circ} 20^{\prime} 56^{\circ} 36^{\prime}$ go mètres (?) Filet de fond. Quatre ex.

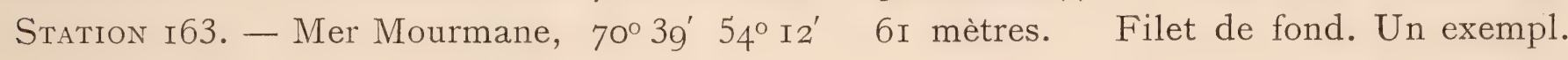

Les spécimens, peu nombreux, ayant perdu la plupart de leurs appendices et une grande partie de leurs élytres, ne dépassent guère 3 millimètres de longueur.

\section{Famille des Syllidiens Grube}

\section{Genre Syllis Savigny}

\section{Syllis CErstedi Malmgren.}

Choctosyllis Erstedi Malmaren (I867), p. 162, pl. IX, fig. 5I.

Syllis CErstedi Théel. (1879), p. 40.

Typosyllis Erstedi Marenzeller (I892), Ost Spitz., p. 407, pl. XIX, fig. I.

Matériel Recueilli :

Lat. N Long. E Profondeur

Station 24a $4^{a}$ - Mer de Kara. $72^{\circ} 48^{\prime} 56^{\circ}$ I $8^{\prime}$ Surface. Filet de Damas. Deux exempl. Station 27. - Mer de Kara. $72^{\circ} 42^{\prime} 56^{\circ}$ I $7^{\prime}$ Surface. Filet de Damas. Quatre exempl.

La station $24^{\mathrm{a}}$ a fourni quatre stolons incomplets à soies natatoires bien développées et dont l'un porte une tête de la forme Ioida. Les stolons de la station 27 ont de larges soies dorsales capillaires et des soies ventrales à serpes courtes et longues mélangées, à extrémité très faiblement bifide.

Les grands cirres dorsaux, subégaux, moniliformes, ont une vingtaine d'articles. 


\section{Syllis fasciata Malmgren.}

Syllis fasciata Malmgren (I867), p. 16I, pl. VIII, fig. 47, et pl. IX, fig. 52.

\section{Matériel Recueilli :}

Station i 53. - Porte de Kara, $70^{\circ} 25^{\prime} \quad 57^{\circ} 56^{\prime} 66$ mèt.

Station i54. - Mer Mourmane, $70^{\circ}$ I9 $^{\prime} 56^{\circ} 42^{\prime} 98$ mèt.

Station i 59. - Mer Mourmane, $70^{\circ} 20^{\prime} \quad 56^{\circ} 36^{\prime}$

Station i6I. - Mer Mourmane, $70^{\circ} \cdot 20^{\prime} \quad 56^{\circ} 36^{\prime}$ go mèt. (?) Filet de fond. Un exemplaire.

Quelques spécimens des stations I59 et I6I possèdent six yeux, quatre gros et deux très petits, disposés comme chez la Syllis sexoculata Ehlers. Certains présentent encore antérieurement des traces de bandes brunes transversales. Un spécimen de la station i53 a la partie postérieure régénérée.

\section{Genre Eusyllis Matmgren}

\section{Eusyllis Blomstrandi Malmgren.}

Eusyllis Blomstrandi MaLmGren (I867), p. 159 , pl. VI, fig. $4^{3}$.

Matériel recueilli :

Lat. N Long. E Profondeur

Station I53. - Porte de Kara, $70^{\circ} 25^{\prime} \quad 57^{\circ} 56^{\prime} 66$ mètres. Filet de fond, fauberts. Un ex.

Les cirres pédieux sont massifs, les soies, toutes semblables, ont une courte serpe très nettement bidentée. Les palpes sont gros et courts et peu ou pas moniliformes. En arrière du prostomium s'élève une sorte de collerette tranversale.

La trompe porte deux couronnes de papilles molles, l'une à l'extrémité de la bouche, l'autre autour de la couronne de dents chitineuses, inégales.

\section{Genre Autolytus Grube}

\section{Autolytus prolifer Müller (I).}

Nereis prolifera MÜLLER (I788), P. I 5.

Autolytus prolifera Grube (I85i), p. 62.

Polybostrichus Mülleri Keferstein (I862), p. II3.

Sacconereis helgolandica MAX MÜLLER (I855). 
Matériel RECUEilli

\section{Lat. $N \quad$ Long. $E \quad$ Profondeur}

Station 50. - Mer de Kara, $71^{\circ} 58^{\prime} \cdot 55^{\circ} 49^{\prime}$ Io5-75 mèt. Grand filet Nansen. Un ex. Station I53. - Porte de Kara, $70^{\circ} 25^{\prime} 57^{\circ} 56^{\prime} .66$ mètres. Fil. de fond, fauberts. Un ex.

L'unique spécimen de la station 50 est une femelle avec sac ovigère et longues soies natatoires, c'est la forme Sacconereis helgolandica; celui de la station i53 est la partie antérieure d'une forme souche à soies en alènes, sauf aux premiers pieds.

\section{Autolytus longisetosus Ersted.}

Polybostrichus longisetosus 'Ersted (18433), p. I82, 184, pl. V, fig. 62, 67, 71.

Autolytus longisetosus Malmgren (1867), p. I54, pl. VIII, hig. 38.

Matériel ReCueilli :

Lat. N Long. E Profondeur

Station 8. - Mer de Barents, $72^{\circ} 50^{\prime} \quad 52^{\circ} 20^{\prime}$ Surface. Filet de surface. Un exemplaire.

L'unique exemplaire est un petit mâle, entier, à six sétigères antérieurs, correspondant bien aux figures de Malmgren.

THéel en a recueilli quelques rares exemplaires “ dans le Détroit de Matotchkine, où il se plaisait à frétiller à la surface de la mer par un temps calme ».

\section{Famille des Sphærodorides Malmgren}

Cette famille ne renferme qu'un petit nombre d'espèces, la synonymie en est néanmoins assez embrouillée, surtout en ce qui concerne les dénominations génériques.

Le nom de genre le plus ancien paraît être Ephesia, créé en $184^{3}$ par RathKE pour son Ephesia gracilis. Presque en même temps CERsTED décrivait la même espèce sous le nom de Spharodonm flarum, dont Malmgren montra plus tard l'identité avec l'espèce de RathkE.

Depuis, Johnston créa le genre Bebryce, qu'il remplaça ensuite par Pollicita, le premier nom ayant déjà été employé par. Philippi en I842. En i865 Johnston abandonna le genre Pollicita, ayant reconnu son identité avec Spharodorum.

Il ne restait donc plus en présence que les genres Ephesia et Sphcrodorum et encore MaLmgren supprimait-il ce dernier, conservant seulement le genre Ephesia. Greeff, de son côté, conservait le nom de Spharodorum en en modifiant la diagnose pour y faire rentrer son $S$. Claparedii. 
Levinsen (I883) reprit les deux noms génériques en précisant de la façon suivante les caractères de chacun :

Genre Ephesia Rathke : Côté dorsal avec deux rangées de capsules de la peau en forme de sphères terminées par une petite papille ronde; segment buccal avec une paire d'appendices semblables. Corps long et cylindrique.

Genre Spharodorum Levinsen nec Ersted : Côté dorsal avec six rangées et côté ventral avec quatre rangées de capsules de la peau en forme de sphères sans papille; segment buccal avec une paire d'appendices en forme de massue. Corps court et large. DE SAint-JosePh (I894, p. 38) aurait préféré “ conserver le genre Ephesia pour l'E. gracilis qui n'a que des soies simples et ranger dans le genre Spharodorum toutes les espèces qui ont des soies composées ».

Edmond Perrier (I897, p. I625) conserva le genre Spharodonm sensu Levinsen et le genre Ephesia, mais en démembrant ce dernier et en créant le genre Hypephesia pour les espèces à soies simples telles que l'Ephesia gracilis, solution assez malheureuse, cette espèce étant en réalité le vrai type du genre Ephesia proprement dit.

Depuis P. Moore (Igog, p. 332) a proposé de supprimer le genre Ephesia parce qu'il. a été employé par HubNer en I8I6, antérieurement à RATHKE, pour un genre de Papillons. Il conserve provisoirement le genre Spharodorum dans lequel il verse toutes les espèces connues.

En réalité le genre Ephesia proposé par Hubner en I8I6 ne semble avoir jamais été adopté. Il ne figure plus dans les catalogues de papillons et toutes les espèces pour lesquelles il avait été créé (E. paranympha, E. antinympha, E. grynea, E. Pasithea, E. agamos, E. nymphagoga, E. nymphaea) continuent, comme par le passé, à être rangées dans l'ancien genre Catocala dont Hubner les avait séparées.

Il me semble que c'est faire un usage abusif de la loi de priorité que de supprimer ainsi un genre bien connu, employé sans interruption depuis plus de soixante ans, pour des espèces bien décrites, sous prétexte qu'il a déjà été proposé par un autre auteur pour un groupe d'animaux complètement différents, avec lesquels aucune confusion n'est possible, et alors surtout que ce nom n'a jamais été accepté et qu'il est depuis longtemps abandonné et même inconnu de la plupart des Lépidoptérologistes.

Je conserve donc le genre Ephesia dont le type est l'Ephesia gracilis, suffisamment bien décrit pour qu'il n'y ait aucune ambiguïté. La présence de soies composées me paraît être un caractère trop insignifiant pour justifier la création d'un genre spécial dans une famille où les espèces sont aussi peu nombreuses. La famille des Spharodorides peut donc être divisée en deux genres seulement : Ephesia et Spharodonum dont je modifierai légèrement les diagnoses de Levinsen en les simplifiant de la façon suivante :

Genre Ephesia. - Corps allongé, cylindrique. Côté dorsal avec deux rangées de capsules de la peau en forme de sphères terminées par une petite papille. - Segment buccal avec une paire d'appendices semblables. Quatre yeux (?). - Quatre antennes. Trompe inerme subcylindrique. - Pas de gésier strié. - Soies simples ou composées. 
Genre Spharodorum. - Corps court et large. Côté dorsal avec plus de deux rangées de capsules de la peau en forme de sphères sans papilles. - Segment buccal avec une paire d'appendices en forme de massue. - Deux yeux (?). - Quatre antennes. Trompe inerme, globuleuse. - Gésier en barillet strié. - Soies composées.

\section{EPHESIA}

$$
\begin{aligned}
& \text { I० Soies simples }\left\{\begin{array}{l}
\text { Ephesia gracilis Rathke. } \\
\text { Ephesia papillifer Moore. }
\end{array}\right. \\
& 2^{\circ} \text { Soies composées }\left\{\begin{array}{l}
\text { Ephesia peripatus Claparède. } \\
\text { Ephesia antarctica Mc'Intosh. } \\
\text { Ephesia brevicapitis Moore. }
\end{array}\right.
\end{aligned}
$$

\section{SPHÆRODORUM}

$\left.\begin{array}{l}\text { Six rangs de sphères dorsales et } \\ \text { quatre rangs de sphères ventrales. }\end{array}\right\}$ Sph. Claparedii Greeff.

Dix à douze rangs de sphères dorsales. Sph. mimuta Webster.

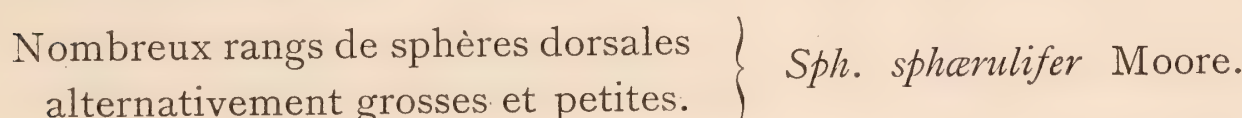

Quatre rangs de sphères dorsales. Sph. Philippi n. spec.

Le Spharodorum Greeffii de GIARD est une espèce nominale qui n'a jamais été décrite par son auteur.

\section{Genre Ephesia RathKe}

(char. emend.)

\section{Ephesia gracilis Rathke.}

Ephesia gracilis Rathke (I843), p. I76, pl. VII, fig. 5-8.

Spharodorum flavum (ERsted (1843), p. 43, fig. 7-92-10I.

Spharodorum peripatus Johnston (1865), p. 208, pl. XIV, fig. I-6.

Bebryce peripatus Johnston, ibid.

Pollicita peripatus Johnston, ibid.

Spharodorum papillifer Moore (I909), p. 333, pl. XV, fig. II, I2. 
Matériel ReCUeilli :

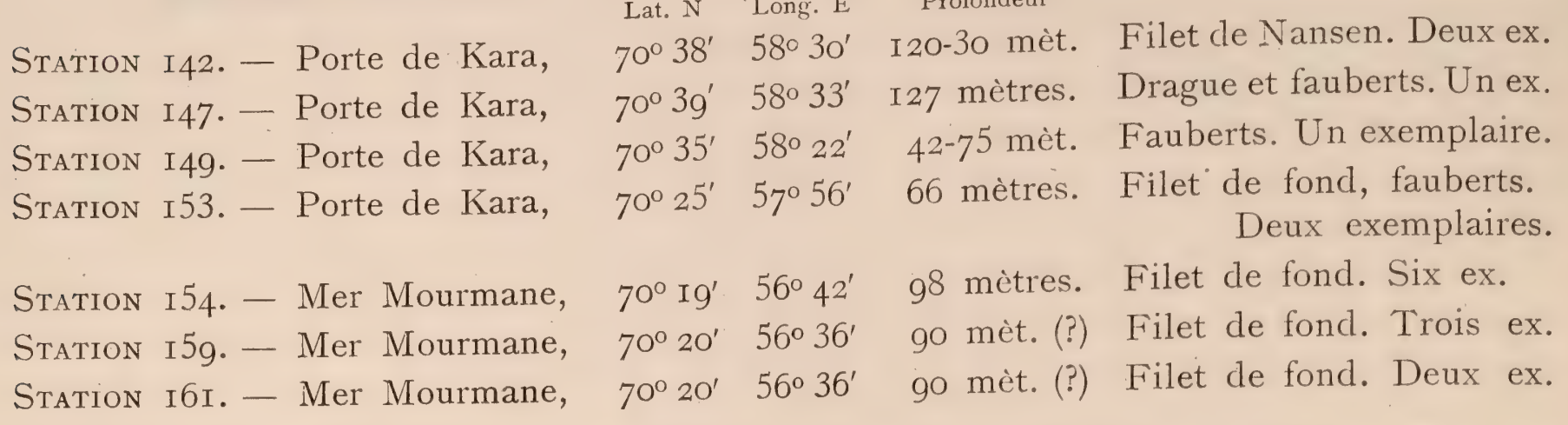

Les nombreux spécimens de cette espèce sont de tailles assez variées. Les uns ont la tête plus ou moins invaginée, comme c'est le cas fréquent chez cet animal; quelques-uns, plus rares, ont la trompe sortie.

Sur la plupart de ceux dont les premiers segments ne sont pas invaginés on distingue bien les quatre taches oculiformes.

La forme exacte du prostomium est plus délicate à déterminer. Les quatre antennes ne diffèrent que bien peu des papilles plus ou moins allongées qui les entourent.

La trompe dévaginée a été bien figurée par Rathke (I843, pl. VII, fig. 5a). Elle ressemble à une trompe d'Eulalia par sa forme générale et les fines papilles dont elle est veloutée.

En arrière des antennes on remarque souvent, de chaque côté, deux papilles cylindriques, un peu plus longues que les autres, déjà figurées par DE SAint-JosepH (I894, pl. III, fig. 52).

$\mathrm{Au}$ premier sétigère il existe déjà, du côté dorsal, une petite capsule sphérique à papille mucronée. Le premier parapode est nettement bifide, les soies émergeant entre deux papilles cirriformes divergentes. Les pieds suivants ont sensiblement l'aspect figuré par CERSted (1843, pl. VI, fig. IOI). Ce sont de courts mamelons hérissés de papilles, mais celles-ci ne me paraissent pas disposées en éventail régulier, comme le décrit DE SAINT-Joseph.

Dans la région moyenne du corps les pieds ont l'aspect que j'ai représenté, (pl. I, fig. 7). Ce sont de gros mamelons coniques, relativement courts, ridés transversalement et couverts de courtes papilles cylindro-coniques disposées sans ordre et assez nombreuses. A la face ventrale, au tiers distal environ, s'insère un cirre ventral semblable à une grosse papille mucronée.

Le parapode est soutenu par un seul gros acicule droit, transparent, incolore.

Les soies, au nombre de quatre à six, sont relativement courtes, trapues, élargies et recourbées au sommet en forme de bec de perroquet (pl. I, fig. 8-9). Le bord concave de la láme et le renflement en forme de garde du même côté sont amincis et parfois finement denticulés. 
Les soies sont toujours toutes simples.

Les téguments, aussi bien à la face dorsale qu'à la face ventrale, sont couverts d'une multitude de petites papilles.

Le segment anal porte deux sphères un peu plus grosses que les précédentes. Sur quelques spécimens on voit encore des restes du cirre anal impair.

Le tube digestif ne possède pas de gésier renflé en barillet strié.

En comparant soigneusement ces exemplaires de la Nouvelle-Zemble à de nombreux spécimens de la Manche, je n'ai pu trouver entre eux la moindre différence.

Je ne puis arriver à trouver une différence entre cette espèce et le Spharodorum papillifer Moore de Californie, à en juger du moins par la description et les figures de l'auteur.

L'Ephesia gracilis, comme l'espèce californienne, possède dorsalement, par rapport aux cirres sphériques, une rangée longitudinale de papilles plus longues que les autres et les appendices de son lobe céphalique ne sont pas toujours plus nets et plus faciles à distinguer des papilles voisines.

\section{Ephesia peripatus Claparède nec Johnston.}

Spharodorum peripatus Claparède (1863), p. 5o, pl. XI, fig. 8-I8.

Ephesia peripatus DE SAINT-Joseph (I894), p. 4 I7.

Ephesia abyssorum Hansen-Levinsen (I883), p. 97.

Spharodorum abyssorum HANSEN (I882), p. 37, pl. VI, fig. I6-I9.

\section{Matériel RECUEilli :}

$$
\text { Lat. N Long. E Profondeur }
$$

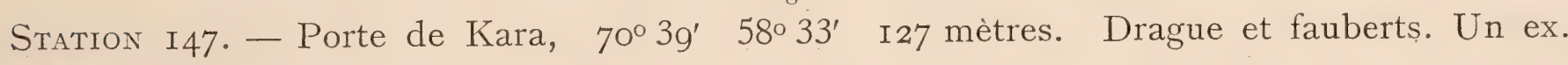

- Cet unique exemplaire mesure 20 millimètres sur 2 millimètres.

La trompe dévaginée est allongée, claviforme, couverte de fines papilles et ressemble tout à fait à celle de l'Ephesia gracilis.

Ses antennes, au nombre de quatre, sont assez petites, subégales, à peine plus développées qu'une papille médiane située en arrière. Le'bord frontal porte une rangée transversale de très fines papilles.

En arrière des antennes on remarque de chaque côté, comme chez l'Ephesia gracilis, deux papilles allongées en forme de tentacules.

Tous ces appendices demanderaient à être étudiés anatomiquement sur des coupes. Les prétendues antennes pourraient bien n'être que des papilles un peu plus développées que les autres.

$\mathrm{Au}$ premier sétigère il existe un petit cirre globuleux et le parapode est bifide, comme formé de deux longues papilles cylindriques, divergentes, entre lesquelles sortent les soies. 
Les pieds typiques du milieu du corps sont un peu plus allongés que dans l'espèce précédente. Ils ont la forme d'un mamelon conique, ridé ou annelé transversalement, portant des papilles cylindro-coniques et terminé en pointe. Le cirre ventral, en forme de papille conique assez grosse, est reporté à l'extrémité du parapode (pl. I, fig. I5) donnant ainsi au pied un aspect bilobé. Dans la région médiane du corps ces deux lobes sont subégaux, la taille du cirre ventral dépassant peu celle du lobe terminal du parapode. Dans le tiers antérieur, comme dans le tiers postérieur du corps, l'inégalité est plus accentuée, le lobe terminal du parapode ne formant plus qu'une petite papille bien moins grosse que le cirre ventral.

Comme chez l'Ephesia gracilis, il n'existe dorsalement, de chaque côté, qu'une seule rangée longitudinale de grosses sphères à papille mucronée. Il existe aussi dorsalement, par rapport au cirre sphérique, une papille allongée, cylindrique. Toute la surface du corps est garnie en outre de fines petites papilles.

Les soies sont toutes composées. La hampe, transparente, s'élargit brusquement, puis elle se termine en biseau sur lequel s'articule l'article terminal en forme de serpe. L'aspect en est assez variable suivant l'angle sous lequel elles se présentent (pl. I, fig. Io à I4). Vues de dos elles paraissent parfois simples.

En résumé, les soies composées et la forme un peu différente du pied et du cirre ventral sont les seuls caractères qui permettent de distinguer cette espèce de l'Ephesia gracilis.

Je suis d'autant moins porté à accorder une valeur générique à ce caractère que Moore signale chez son Spharodorum brevicapitatis de Californie des " soies composées, ou semi-composées, devenant élargies et aplaties à l'extrémité distale, puis s'effilant en crochet ou appendice articulé avec la hampe par un joint oblique dont l'absence laisserait ces soies très semblables à celles du S. papillifer ».

Mc'Intosh (Igo8, p. 529) mentionne une forme des îles Anglo-Normandes à soies articulées - qui pourrait bien être l'Ephesia peripatus - dont certaines soies montrent une soudure de l'article terminal les transformant en soies du type E. gracilis.

Chez certains Euniciens (Omuphis conchylega, par exemple) on trouve, suivant l'âge, tous les passages entre la soie entière, pseudo-articulée et nettement articulée. Il n'y a donc pas lieu d'attacher une importance exagérée à ce caractère.

Chose bizarre, l'Ephesia gracilis et l'Ephesia peripatus se rencontrent dans les mêmes localités, parfois dans les mêmes stations (St. I47), mais tandis que la première y est relativement abondante la seconde paraît être beaucoup plus rare, ainsi que DE SAinTJoseph l'a constaté à Dinard et que je l'ai observé à Saint-Vaast-la-Hougue et sur le matériel ci-dessus.

N'y aurait-il pas là un phénomène analogue à l'épitokie ou un dimorphisme sexuel?

L'exemplaire ci-dessus est une femelle renfermant une assez grande quantité de gros œufs discoïdes, à noyau plus clair, analogues aux "corpuscules » décrits par Webster et Benedict chez l'Ephesia mimuta. 
Le Spharodorum abyssorum, si brièvement et si incomplètement décrit par Hansen, ne me paraît pas différer de l'Ephesia peripatus dont il a les soies composées et la même disposition des pieds et des sphères dorsales.

L'Ephesia antarctica Mc'Intosh et le Spharodonum brevicapitis Moore sont deux espèces ayant de grandes affinités avec l'Ephesia peripatus.

\section{Genre Sphærodorum ERsted}

(sensu LEVINSEN char. emend.)

Spharodorum Philippi n. spec.

Matériel RECUeilli :

Lat. $\mathrm{N}$ Long. E Profondeur

Station I03. - Mer de Kara, $71^{\circ} 32^{\prime} \quad 57^{\circ}$ Io' $220-0$ mètres. Grand filet Nansen. Un ex.

Diagnose. - Corps court, aplati. - Quatre antennes; deux cirres tentaculaires. Quatre rangées dorsales de capsules sphériques sans papilles; pas de capsules sphériques à la face ventrale. - Longs parapodes cylindro-coniques, annelés. - Soies composées à long article terminal. - Gésier en barillet strié.

L'unique spécimen recueilli est de très petite taille, il mesure à peine 3 millimètres de longueur. Le corps, de couleur blanchâtre, est assez large, trapu, un peu aplati. La trompe dévaginée et déchirée a entraîné au dehors une partie du tube digestif.

Le nombre des sétigères est de quinze.

Le prostomium, dont le bord est difficile à distinguer par suite de l'extension brutale de la trompe, porte quatre antennes papilliformes, assez longues, subégales entre lesquelles on remarque de petites papilles.

En arrière deux grandes papilles sont peut-être des cirres tentaculaires (pl. I, fig. I7).

$\mathrm{Au}$ premier sétigère le parapode est bifurqué, les soies sortent entre deux papilles (cirres ?) divergentes, subégales. Dorsalement le pied est surmonté de deux papilles sphériques.

Dans la région moyenne du corps les parapodes sont relativement longs, presque cylindriques, annelés et terminés par un gros lobe conique sous lequel sortent les soies. Le parapode porte plusieurs papilles cylindriques ou coniques. A sa face ventrale s'insère un cirre conique bien développé, mais cependant toujours moins gros que le lobe terminal du pied (pl. I, fig. I8 et Ig).

Le parapode est soutenu par un acicule droit, transparent, pointu. 
Les soies, longues et fines, sont au nombre de huit à dix dans les pieds bien développés. Elles portent à leur extrémité un long article, bien détaché, plutôt en forme d'arête que de serpe (pl. I, fig. I6). L'articulation est très oblique.

A la face dorsale, de chaque côté du corps, s'étendent deux rangées de grosses capsules sphériques, sans papille mucronée, mais présentant parfois de petites verrues à leur surface, visibles seulement à un fort grossissement. En dessus de ces capsules sphériques, par- rapport au pied, il n'y a pas de longues rangées de papilles cylindriques comme chez les Ephesia.

Il semble que la sphère supérieure soit l'homologue de cette papille cylindrique dont elle occupe la place.

En dehors des quatre rangs de grosses sphères dorsales, toute la surface du corps est couverte de petites papilles coniques ou cylindro-coniques.

Le pygidium, vu par la face dorsale, présente un bord arqué portant quatre papilles.

$\mathrm{Au}$-dessus du dernier sétigère on remarque deux groupes de trois capsules cylindriques ou plutôt piriformes (pl. I, fig. 20).

De ces trois paires de capsules deux appartiennent au dernier sétigère, tandis que la troisième, un peu plus grosse, appartient sans doute au pygidium.

Les derniers sétigères sont fortement bifurqués en deux lobes coniques subégaux.

A l'intérieur du corps on distingue, par transparence, une dizaine de grosses masses ovoïdes, blanchàtres, opaques, avec une tache centrale claire, qui me paraissent être des œufs.

Greefr a constaté aussi la présence de gros oufs chez son Spharodonm Claparedii. et les grandes cellules dișcö̈dales de. l'Ephesia mimuta, décrites par Webster, en sont aussi probablement.

Je n'ai pu voir d'yeux en arrière des antennes, mais, vu l'état de cette région, ils ont pu m'échapper.

La trompe dévaginée est malheureusement déchirée; elle a entraîné avec elle une. partie de l'appareil digestif dont le gésier se présente sous l'aspect d'une grosse masse ovoïde striée, un peu analogue au barillet des Syllidiens (p. I, fig. I7) et que je ne saurais mieux comparer qu'à une coquille de Trivia europaa.

Cette espèce, par la forme du corps et son aspect général, se rapproche du Spharodorum Claparedii de Greerf, provenant de Dieppe.

Mais l'espèce de GreEFF a dix rangées de capsules sphériques : six dorsales et quatre ventrales, tandis que le S. Philippi n'en a que quatre dorsales et pas de ventrales. Les parapodes du S. Claparedii portent à leur extrémité deux gros lobes égaux, dilatés en massue, entre lesquels sortent des soies de forme un peu différente.

L'Ephesia mimuta Webster, qui est en réalité un vrai Spharodorum, a dix à douze rangs de sphères dorsales. Ses parapodes ressemblent davantage à ceux du S. Philippi, mais les soies ont un article beaucoup plus court. 
Le Spharodonum spharnlifer de MOORE porte de nombreuses sphères dorsales, alternativement grosses et petites, insérées sur une crête tranisversale irrégulière.

Les Sphcrodorum paraissent être tous des espèces de petite taille; le Sph. Claparedii mesure 2 millimètres, le Sph. minutum 3 à 4 millimètres, le Sph. Philippi 3 millimètres. Ce sont cependant des Annélides adultes puisque chez les trois espèces ci-dessus on a constaté la présence de gros œufs.

DE Saint-Joseph range les Sphærodorides entre les Glycériens et les Cirratuliens.

Leurs affinités me paraissent être plutôt avec les Syllidiens. Indépendamment de leur ressemblance avec les Eurysyllis, porteurs également de cirres dorsaux sphériques, leurs pieds, leurs soies les rapprochent des Syllidiens, et le gésier des Spharodorum rappelle le barillet strié si fréquent dans cette famille.

\section{Famille des Euniciens sensu GruBE}

Genre Onuphis Aud. et Edw.

(sensu Langerhans, de Saint-Joseph, Gravier)

\section{Onuphis conchylega Sars.}

Onuphis conchylega SARS (I835), pp. 6I-63, pl.' X, fig. 28.

Northia conchylega MaLmgren (1867), p. 180.

Nothria conchylega Mc'Intosh (1878), p. 503.

Onuphis Eschrichti ERSTED (I8433), p. 20, pl. III, fig. 33.

Diopatra Eschrichti GRUBE (185I), p. 43.

Onuphis hyperborea HANSEN (1880), p. 32, pl. IV, fig. 5-I3.

\section{Matériel Recueilli :}

$\begin{array}{lcccc}\text { Lat. N } & \text { Long. E } & \text { Profondeur } & \\ \text { Station 79. - Mer de Kara, } & 71^{\circ} 39^{\prime} & 56^{\circ} \mathrm{O} 2^{\prime} & \text { I34 mètres. Fauberts. Un exemplaire. }\end{array}$

Station i35. - Mer de Kara, $7 \mathrm{I}^{\circ} \mathrm{O}^{\prime} \quad 57^{\circ} 55^{\prime}$ 2I 2 mètres. Filet de fond. Un exempl.

Station I46. - Porte de Kara, $70^{\circ} 40^{\prime} \quad 58^{\circ} 33^{\prime}$ ' 35 mètres. Fauberts. Un exemplaire.

Station i59. - Mer Mourmane, $70^{\circ} 20^{\prime}$ 56 36' go mèt.(?) Filet de fond. Un exempl.

Station i6i. - Mer Mourmane, $70^{\circ} 20^{\prime \prime} 56^{\circ} 36^{\prime} \quad 90$ mèt.(?) Filet de fond. Un exempl.

Tous les exemplaires recueillis portent encore des bandes rougeâtres transversales tranchant vivement sur un fond plus clair. Cette coloration rayée alternativement de rouge et de blanc rappelle tout à fait celle des Nereis zonata des mêmes régions.

Les premiers sétigères portent de grosses soies jaunes, recourbées en croc, mais dès le deuxième sétigère apparaissent les soies pectinées et les soies capillaires. Les 
tubes, caractéristiques, comprimés, sont tantôt revêtus de graviers minces et de grands fragments plats de coquilles, tantôt recouverts de graviers plus ou moins épais, noirs, blancs, jaunes, mélangés de quelques foraminifères.

Il est évident que l'animal utilise les matériaux à sa portée, et ces différences dans la forme et la composition du tube n'ont aucune importance spécifique, ainsi que je l'ai déjà fait remarquer. (FAuvel, IgI I ${ }^{a}$, p. 4.)

\section{Genre Lumbriconereis Blainville}

(Grube rev. incl. Zygolobus Grube)

Lumbriconereis fragilis O. F. Müller.

Lumbricus fragilis O. F. MüLler (1776), p. 26 I I (I777), t. I, p. 22, pl. XXII, fig. I-3.

Lumbriconereis fragilis ERSTED $\left(184^{\mathrm{b}}\right)$, p. 15 , fig. I-2.

Lumbriconereis fragilis MALMGREN (1867), p. I78, pl. XV, fig. 83.

Lumbriconereis borealis KINBERG (I864), p. 568.

Matériel Recueilli :

Lat. $\mathrm{N}$ Long. $\mathrm{E} \quad$ Profondeur

Station 222. - Océan Glacial, $77^{\circ} 46^{\prime} 64^{\circ}$ I $4^{\prime} \quad 290$ mètres. Sondeur Gilson. Un exempl.

Cette espèce n'est représentée que par la partie antérieure d'un petit spécimen à lobe céphalique en ogive pointue. Les soies à crochet se montrent au seizième sétigère. Il n'y a pas de soies composées.

\section{Lumbriconereis minuta THÉEL.}

Lumbriconereis minuta THéEL (1879), p. 42, pl. IV, fig. 57-59.

(?) Lumbriconereis fragilis LEVINSEN (1883), p. 284.

\section{Matériel Recueilli :}

Station i54. - Mer Mourmane, $70^{\circ} 19^{\prime} 56^{\circ} 42^{\prime} 9^{8}$ mètres. Filet de fond. Trois exempl.

Les trois petits exemplaires de cette station mesurent de I2 à I5 millimètres sur 0.5 à 0.7 millimètre.

Les mâchoires sont semblables à celles figurées par THÉEL. Les soies à crochet apparaissent du premier au troisième sétigère, suivant les individus. C'est surtout ce dernier caractère qui distingue cette espèce de la $L$. fragilis. LEvinsen (I883, $2^{\mathrm{e}}$ partie, p. 284) les réunit et considère la L. minuta comme une forme jeune de L. fragilis, opinion qui me paraît assez probable. 


\section{Famille des Néréidiens Quatrefages}

\section{Genre Nereis Cuvier}

Sous-genre Nereis s. stric. KINBERG

Nereis zonata Malmgren.

Nereis zonata MaLmgren (1867), p. 164 , pl. VI, fig. 34 .

Nereis zonata EHLers (I868), p. 5 Io.

Nereis zonata Fauvel (IgII), p. 385, pl. XIX, fig. ro-I6, I8-23, pl. XX, fig. 24-25.

Nereis procera Ehlens (1868), p. 557, pl. XXIII, fig. 2.

Nereis procera Langerhans (1879), p. 285, pl. XV, fig. $2 \mathrm{I}$.

Nereis procera DE SAint-Joseph (I887), p. 226, pl. XI, fig. I32.

Nereis procera Johnson (190I), p. 400, pl. IV, fig. 47, pl. V, fig. 53-59.

Heteronereis grandifolia MALMGReN (1865), pl. XI, fig. I6, I6 $6^{\text {a. }}$

\section{Matériel RECUEILli :}

Station I34. - Mer de Kara, ' $71^{\circ} 02^{\prime} \quad 57^{\circ} 50^{\prime}$ 210 mètres. Fauberts. Un exemplaire.

Station I53. - Porte de Kara, $70^{\circ} 25^{\prime} \quad 57^{\circ} 56^{\prime} \quad 66$ mètres. Filet de fond, faubts. Un ex.

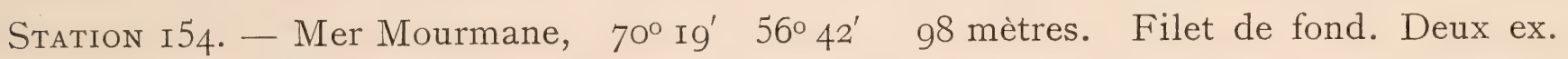

Station I59. - Mer Mourmane, $70^{\circ} 20^{\prime} \quad 56^{\circ} 36$ Exploration d'une grande dalle voisine du navire. Sable, pierres, algues, coquilles. Quatre exemplaires.

Station i6i. - Mer Mourmane, $70^{\circ} 20^{\prime} 56^{\circ} 36^{\prime}$ go mètres. Filet de fond. Huit exempl. Station i65. - Baie Gribovaya, $73^{\circ}$ oo' 53 I 5' Sur l'estran à mer basse. Un ex. épitoke.

La taille des spécimens recueillis varie entre 15 millimètres et 60 millimètres de longueur, les plus grands ne dépassent guère 3 à 4 millimètres de large, pieds compris.

Presque tous présentent encore très nettement, au moins dans leur région antérieure, des bandes transversales alternativement rougeâtres et blanchâtres. Cette coloration zonée rappelle celle de l'Omphis conchylega des mêmes parages.

Le spécimen de Gribovaya est une femelle épitoke de grande taille (65 millimètres sur I2 millimètres), à coloration d'un rouge vineux assez uniforme coupée d'étroites zones claires intersegmentaires. 
La Nereis zonata, qui n'est peut-être qu'une simple variété de la Nereis pelagica, se distingue principalement de cette dernière par sa coloration rayée transversalement et par le nombre et la disposition de ses paragnathes des groupes I et V.I.

Chez la Nereis pelagica, les paragnathes du groupe I varient entre un et trois, deux étant le nombre le plus fréquent. Aux groupes VI on trouve le plus souvent quatre, parfois cinq gros paragnathes coniques disposés en carré.

Chez la Nereis zonata, au groupe I, on trouve zéro ou un seul paragnathe, aux groupes VI le nombre des paragnathes est très variable, mais le plus souvent supérieur à cinq et pouvant atteindre dix ou douze. En outre, ces paragnathes sont d'ordinaire plus petits que ceux de Nereis pelagica et disposés sans ordre sur une aire ovale.

Enfin, chez la Nereis zonata, les antennes sont plus longues, les cirres dorsaux postérieurs plus courts et les lobes parapodiaux plus pointus que chez la Nereis pelagica, mais ces trois derniers caractères sont loin d'être constants et présentent une grande variabilité. (Pl. I, fig. 4.)

Chez la Nereis zonata de la Nouvelle-Zemble, voici les variations que je note en ce qui concerne le nombre des paragnathes des groupes I et VI :

$\begin{array}{cc}\text { Groupe I } & \text { Groupe VI } \\ \text { ग } & 3-3 \\ \text { I } & 4-4 \\ \text { I } & 4-3 \\ \text { O } & 5-4 \\ \text { I } & 6-10 \\ \text { O } & 4-6 \\ \text { ग } & 7-7 \\ \text { O } & 7-6\end{array}$

Sur plusieurs spécimens je trouve soixante-douze à soixante-quinze sétigères.

La grosse soie en serpe homogomphe de la rame dorsale apparaît vers le trentième sétigère chez les individus de taille moyenne et vers le vingt ou vingt-cinquième chez les petits. Elle avait échappé à Malmaren et à Ehlers.

Cette grosse serpe ne diffère d'ailleurs pas de celle que l'on observe chez la Nereis pelagica et chez la Nereis procera, dont elle fut d'abord considérée comme caractéristique. Suivant l'âge de l'animal et l'usure de la soie, cette serpe présente d'ailleurs des différences notables. (Pl. I, fig. I, 2, 3.)

Chez les jeunes, l'article terminal de ces soies porte sur son bord concave plusieurs dents aiguës terminées par un poil rigide. (Pl. I, fig. 3.)

Plus tard, on n'observe plus que deux ou trois grosses dents plus ou moins émoussées, mais encore bien nettes. (P1. I, fig. I-2.) Enfin, sur les serpes usées des vieux spécimens, l'article terminal de la soie n'est plus qu'un croc arrondi, à peine recourbé et plus ou moins complètement enfoncé dans l'articulation homogomphe. 
La grosse forme épitoke o de Gribovaya (pl. I, fig. 5) ne diffère de la forme Heteronereis o de la Nereis pelagica que par sa coloration zonée. La trompe porte un paragnathe au groupe I et quatre paragnathes, de chaque côté, au groupe VI.

Théel (I879, p. 42) avait trouvé dans la Mer de Kara l'Heteronereis grandifolia Mgr. et l'Heteronereis assimilis Ersted, jusqu'ici considérées comme les formes sexuées de la Nereis pelagica, mais n'ayant jamais rencontré cette dernière espèce dans les parages de la Nouvelle-Zemble, il rapporta, avec raison, à notre avis, les formes qu'il avait recueillies à la Nereis zonata.

J'ai déjà montré (IgI I ${ }^{\mathrm{b}}, \mathrm{p}$. 39I) que l'Heteronereis grandifolia $\mathrm{o}^{\mathrm{a}}$, telle qu'elle est figurée par Malmgren ( $\mathrm{I} 865, \mathrm{pl}$. XI, fig. I6 et $\mathrm{I} 6^{\mathrm{a}}$ ) est la forme épitoke o de la Nereis zonata, ainsi que l'indiquent le nombre et la disposition des paragnathes des groupes VI.

Quant à l'Heteronereis assimilis Ersted ( $=H$. grandifolia o de MaLmaren), elle paraît être la forme sexuée femelle de la Nereis pelagica. Mais l'Heteronereis de Gribovaya, que sa coloration nous fait rattacher à la Nereis zonata, ne paraît pas en différer notablement. Ceci nous paraît un argument de plus en faveur. de notre hypothèse, d'après laquelle (IgII ${ }^{\mathrm{b}}$, pp. 389, 39I) la Nereis pelagica et la Nereis zonata ne seraient que deux variétés extrêmes d'une même espèce, la Nereis procera, représentant une forme intermédiaire, mais plus voisine cependant de $N$. zonatd que de $N$. pelagica.

Dans la Manche, la Mer du Nord, la Mer d'Irlande, cette forme procera est très abondante dans les dragages. MalaQuin (I89o) et Southern (IgIo) l'ont décrite sous le nom de Nereis zonata; DE SAINT-Joseph, après. l'avoir d'abord décrite sous le nom de Nereis procera Ehlers, l'a ensuite rattachée à la Nereis pelagica.

Cette forme procera ne diffère de la Nereis zonata arctique que par l'absence de coloration. nettement zonée. Elle serait donc simplement une variété méridionale ex colore de cette dernière. Encore présente-t-elle parfois des traces de bandes rougeâtres transversales.

Les paragnathes des groupes I et VI présentent les mêmes, variations de nombre que chez les spécimens de $N$. zonata de la Nouvelle-Zemble.

Si nous admettons que la $N$. procera se confond avec la $N$. zonata, nous voyons que la distribution géographique de cette espèce est très étendue et loin d'être limitée aux régions arctiques, comme on le supposait jusqu'ici.

Parmi des Annélides du Golfe Persique, j'ai trouvé en abondance une petite Nereis ne différant de la $N$. zonata que par des caractères insignifiants, justifiant tout au plus la création d'une variété persica.

La distribution géographique de la N. zonata comprend alors les Mers Arctiques, la Baltique, la Mer du Nord, la Mer d'Irlande, la Manche, l'Océan Atlantique, le Golfe Persique et l'Océan Pacifique.

La distribution géographique de la $N$. pelagica est sensiblement la même. 


\section{Famille des Phyllodociens GrUBE}

\section{Genre Phyllodoce Savigny}

\section{Phyllodoce groenlandica Ersted.}

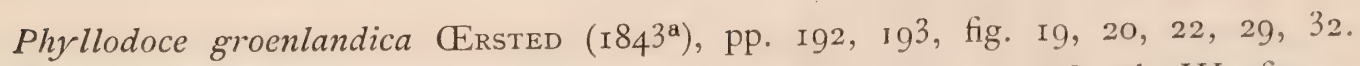

Phyllodoce groenlandica Malmgren (i865), p. 96 (I867), p. I43, pl. III, fig. 9.

\section{Matériel Recueilli :}

Lat. $N^{\prime}$ Long. E Profondeur

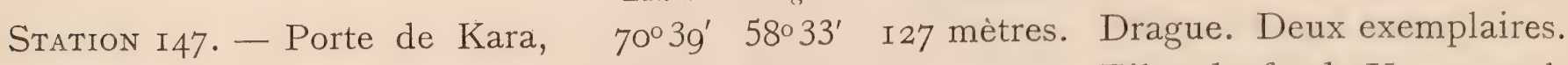

Station i63. - Mer Mourmane, $70^{\circ} 39^{\prime} 54^{\circ}$ I $^{\prime}$ 6I mètres. Filet de fond. Un exempl. Station I75. - Matotchkine Char, $73^{\circ} 24^{\prime} 54^{\circ} 5 I^{\prime} \quad$ I mètre. Petite drague triang. Un ex.

Le plus grand spécimen mesure environ 20 centimètres de long. Ces exemplaires, bien typiques, ne diffèrent pas de ceux que l'on récolte dans le sable, sur les côtes de la Manche.

\section{Genre Anaïtis Malmgren}

\section{Anaïtis Wahlbergi Malmgrem.}

Anaïtis Wahlbergi Malmgren (I865), p. 94, pl. XIV, fig. 3 I.

Anaïtis Kosteriensis Mc'Intosh (Ig08), p. 72, pl. LVIII, fig. 6; pl. LXVIII, fig, I4, I5.

Anaïtis Kosteriensis Malmgren (1867), p. I42.

MAtériel RECUEILli :

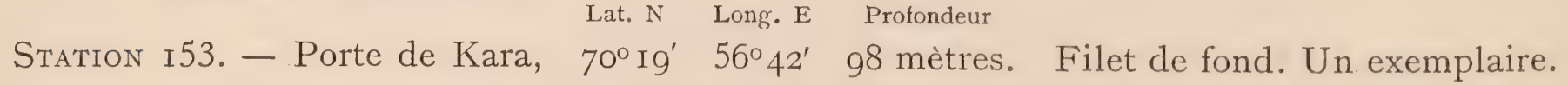

Le seul exemplaire est un fragment antérieur dont la trompe et l'intestin font à moitié hernie à l'extérieur. La trompe, longue et sinueuse, porte deux rangées de papilles nombreuses (trente à quarante), coniques, aplaties, très serrées. Les deux bandes latérales sont séparées par un large champ dorsal et un ventral. LEvinsen mentionne sur la trompe deux bandes pectinées de papilles foliacées, pointues, disposées en zigzag sur deux rangs, de chaque côté. L'Anaïtis Kosteriensis figuré par Mc'Intosh (I908, p. 72, pl. LVIII, fig. 6, pl. LXVIII, fig. I4, I5) ne me paraît pas différer de cette espèce. LEVINSEN admet aussi leur identité. 


\section{Genre Eteone SavignY}

\section{Eteone depressa Malmgrem.}

Eteone depressa Malmgren (I865), p. 103, pl. XV, fig. 36.

Eteone depressa Théel (1879), p. 32, pl. II, fig. I9.

Matériel RECUEILli :

Lat. N Long. E Profondeur

Station i59. - Mer Mourmane, $70^{\circ} 20^{\prime}$ 56 36' 90 mètres (?) Filet de fond. Un exempl.

L'unique exemplaire mesure 52 millimètres sur 2 millimètres. Contrairement à ce que ThéEl a observé, les yeux ne sont pas visibles. Les cirres tentaculaires sont très courts, le supérieur est plus petit que l'inférieur. Les parapodes correspondent bien aux figures de ThéEL (pl. I, fig. 6). Les lobes en sont plus arrondis que ceux de l'Eteone spetsbergensis qui sont ovales, à grand axe presque vertical. La tête, un peu moins large, est sans yèux, comme l'a observé Malmgren. Par contre, les figures de cet auteur rendent moins bien les pieds qui ressemblent plutôt à ceux figurés par Mc 'InTosh (Igo8:? p. I04, pl. LXIX, fig. 5-6) pour l'Eteone spetsbergensis. En somme ces deux espèces sont bien voisines, sinon identiques.

\section{Famille des Nephthydiens GRUBE}

\section{Genre Nephthys Cuvier}

Nephthys ciliata Müller (I).

Nereis ciliata MüLLER (I 788 ), pl. LXXXIX, fig. I-4.

Nephthys borealis (ERSTED $\left(\mathrm{I} 84^{\mathrm{b}}\right)$, p. 32.

Nephthys ciliata Malmaren (1865), p. I04, pl. XII, fig. 17.

Matériel Recueilli :

Lat. $N \quad$ Long. $\mathrm{E} \quad$ Profondeur

Station I46. - Porte de Kara, 70 40' 58033' i35 mètres. Fauberts. Un exemplaire.

(I) Pour la bibliographie, voir Mc'Intosh (1908, p. 24). 
L'unique exemplaire de grande taille, tronqué postérieurement, mesure go millimètres sur to millimètres, pieds compris. La trompe, dévaginée, porte une grande papille isolée en avant des autres.

Les parapodes correspondent bien aux descriptions et aux figures de THÉEL (1879) et d'Ehlers (I868).

Nephthys paradoxa Malm. (1874, p. 77).

Nephthys paradoxa Malm.-Théel (I879), p. 3i.

Nephthys paradoxa Levinsen (i883), p. 59 (i886), p. 8.

Nephthys pansa EHLERs (I874), p. 40, pl. III, fig. I-2.

Nephthys pansa Horst. (I88I), p. 7 .

Nephthys pansa Mc' Intosh (I908), p. 4I, fig. 40.

\section{MATÉRIEL RECUEILli :}

Lat. $\mathrm{N}$ Long. $\mathrm{E} \quad$ Profondeur

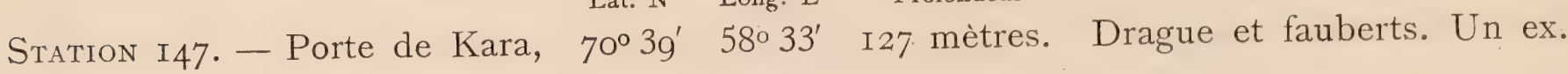

Cette espèce n'est représentée que par un fragment antérieur d'un très gros spécimen mesurant I IO millimètres sur I2 millimètres.

La trompe, dévaginée, porte vingt-deux rangées longitudinales de grosses papilles bifides au nombre de quatre à six par rangée et parfois, en outre, une ou deux autres petites plus éloignées. A la face dorsale il existe, entre les deux premières rangées, mais ne les dépassant pas, une papille impaire, de même taille. A la face ventrale, il existe aussi une papille impaire, plus courte que les autres, et une bifide.

Le lobe céphalique, plus large que long sur la trompe dévaginée, est semblable à celui figuré par EHLers.

Les rames des premiers parapodes sont très écartées, très courtes, à lamelles peu marquées. Les soies sont disposées sur une ligne en forme d'U au centre duquel fait saillie la pointe de l'acicule, recouvert d'un capuchon chitineux, brun, renflé en chou-fleur.

Aux premiers sétigères, la branchie est presque nulle. Ensuite, vers le vingtdeuxième sétigère, elle devient triangulaire comme la figure Ehlers. Vers le vingtcinquième sétigère, elle s'allonge et porte un très petit cirre dorsal. Vers le vingt-huitième ou trentième sétigère elle est en forme de faucille et lamelleuse.

\section{Nephthys Malmgreni Théel.}

Nephthys longisetosa (nec Ersted) Malmgren (1865), p. io6, pl. XII, fig. 20.

Nephthys longisetosa Ehlers (1871), p. 79. Marenzeller (I877), p. 39.

Nephthys Malmgreni THÉEL (1879), p. 26, pl. I, fig. 17; pl. II, fig. I7. 
Matériel Recueilli :

Station 67. - Mer de Kara, $71^{\circ} 49^{\prime} \quad \begin{array}{lll}\text { Long. } & 55^{\circ} 52^{\prime} & \text { Profondeur } \\ \text { I } 23 \text { mètres. Drague et fauberts. Un ex. }\end{array}$

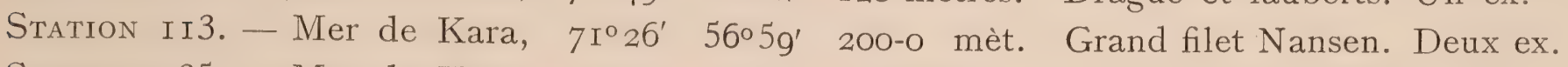

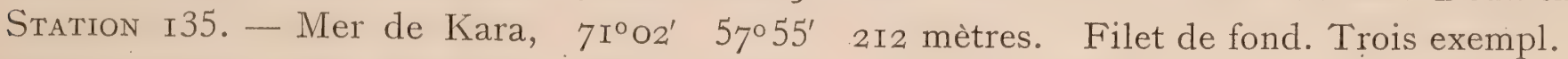

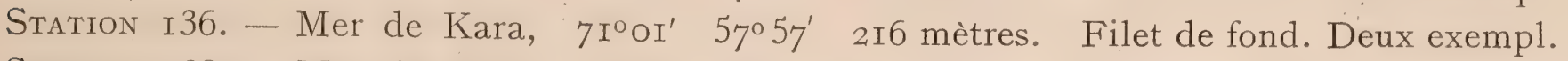
Station I38. - Mer de Kara, 70 58' 58004' 212 mètres. Filet de fond. Un exemplaire.

Les exemplaires sont assez nombreux et de tailles variées. La trompe porte quatorze rangées de. douze à treize papilles décroissant très régulièrement de longueur d'avant en arrière.

Les dix à quinze premiers sétigères sont dépourvus de branchies. En général la première branchie se montre au quatorzième sétigère. Les branchies sont ensuite bien développées, longues, enroulées en spirale. Elles disparaissent de nouveau dans la région postérieure du corps.

Les rames parapodiales sont pointues et portent de longues soies caractéristiques.

THÉEL avait trouvé cette espèce en grande abondance dans la Mer de Kara.

Ainsi que cet auteur l'a reconnu, cette espèce décrite par. MALMGREN sous le nom de Nephthys longisetosa Crsted est bien différente de l'espèce d'Grsted. C'est donc avec raison qu'il lui a donné le nom de Nephthys Malmgreni.

Mc'Intosh (Igo8, p. 3o) reprend l'ancien nom et confond de nouveau les deux espèces. Sa description diffère notablement de celle de THéEL et de ce que nous avons observé ci-dessus. Il ne mentionne pas l'absence de branchies aux dix à quinze premiers sétigères et à la région postérieure.

\section{Famille des Cirratuliens V. Carus}

\section{Genre Chatozone MaLmGREN}

\section{Chatozone setòsa Malmgren.}

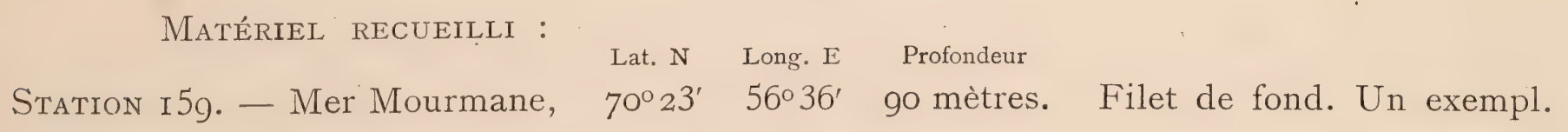

Ce petit spécimen mesure seulement 4 millimètres sur 0.5 millimètre. Les gros tentacules sont tombés, mais on voit encore la trace de leur insertion en avant du premier sétigère. Les soies ne sont pas encore très longues. Aux parapodes postérieurs les soies aciculaires des deux rames, bien que tendant à se rejoindre, ne forment pas 
encore la ceinture complète des adultes. ThéEL a déjà constaté ces caractères sur de jeunes spécimens. Chez les adultes arrivés à maturité les palpes tombent, les soies dorsales deviennent très longues, les soies aciculaires de la région postérieure sont disposées en ceinture autour du segment. Ces modifications sont liées à l'épitokie.

\section{Famille des Spionidiens SARS}

\section{Genre Aonides Claparède}

\section{Aonides cirrata Sars.}

Nerine cirrata SARS (I85I), p. 252.

Scolecolepis cirrata MaLMGRen (I867), p. I99, pl. IX, fig. 54.

Spio cirratus Levinsen (I883), p. I03.

Laonice cirrata Mesnil (I896), p. 247.

Matériel Recueilli :

Lat. N Long. E Profondeur

Station i54. - Mer Mourmane, $70^{\circ} 19^{\prime} \quad 56^{\circ} 42^{\prime} 98$ mètres. Filet de fond. Un exempl.

Le spécimen unique consiste en un fragment postérieur, facilement reconnaissable, cependant, à ses poches latérales en forme de hamac, désignées par MöBuUs sous le nom d' "Eiertaschen » et revues aussi par ThéEL.

\section{Famille des Flabelligériens dE SAInt-Joseph}

(Phérusiens Grube, Chlorhémiens Quatrefages)

\section{Genre Flabelligera SARS}

\section{Flabelligera affinis Sars.}

Chlorama Edwardsi Dujardin (1839), p. 288, pl. VII, fig. I-5.

Siphonostoma vaginiferum Rathke (1843), p 210, pl. XI, fig. 3 Iо.

Chlorama sordidum Quatrefages (1865), t. I, p. 474, pl. XII, fig. 3-6.

Chlorama Dujardini Quatrefages (1865), t. I, p. 472, pl. I, fig. 2.

Chlorama pellucidum G. O. SARS (I87I), p. 400.

Flabelligera affinis MaLMGREN (1867), p. I93. 
Matériel Recueilli :

Station r53. - Porte de Kara, $\quad 70^{\circ} 25^{\prime} \quad 57^{\circ} 06^{\prime} \quad 66$ mètres. Filet de fond, faubts. Deux ex. Station 154. - Mer Mourmane, $70^{\circ} \mathrm{Ig}^{\prime} \quad 56^{\circ} 42^{\prime} \quad 9^{8}$ mètres. Filet de fond. Un exemplaire.

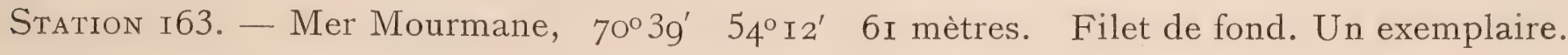

Tous ces exemplaires, en assez mauvais état, enrobés de boue, ont perdu la plus grande partie des soies de leur cage céphalique.

\section{Genre Stylariö̈des Delle Chiaje}

Stylarioüdes plumosa O. F. Müller.

Amphitrite plumosa Müller (I779), Zool. Dan., t. III, p. I6, pl. XC, fig. I-2.

Flabelligera plumosa SARS (1835), p. 47.

Siphonostomum plumosum Rathke (I843), p. 208, pl. XI, fig. I-2.

Pherusa obscura Quatrefages (I865), t. I, p. 479, pl. XII, fig. 7.

Trophonia plumosa MALMGRen (1867), p. I92.

Trophonia arctica HANSEN (I882), p. 230.

Trophonia borealis HANSEN (I882), p. 230.

Trophonia rugosa Hansen (1882), p. 23 I.

Pherusa Mulleri Oken, Quatrefages (I865), p. 282.

Matériel Recueilli :

Lat. N Long. E Profondeur

Station I46. - Porte de Kara, $70^{\circ} 40^{\prime} \quad 58^{\circ} 33^{\prime}$ i 35 mètres. Fauberts. Un exemplaire.

Station i54. - Mer Mourmane, $70^{\circ} \mathrm{Ig}^{\prime} \quad 56^{\circ} 42^{\prime} 98$ mètres. Filet de fond. Un exempl.

Station I59. - Mer Mourmane, $70^{\circ} 20^{\prime} \quad 566^{\circ} 36$ 9o mètres. Filet de fond. Un exempl.

Tous les spécimens sont plus ou moins tronqués postérieurement. Celui de la station $\mathrm{I}_{4}$ est brun rouille, celui de la station $\mathrm{I} 59$ est très gros et noirâtre.

\section{Famille des Scalibregmidés Malmgren}

\section{Genre Pseudoscalibregma Asнwовтн}

\section{Pseudoscalibregma longisetosum Théel.}

Eumenia longisetosa Théel (I879), p. 49, pl. III, fig. 45-47; pl. IV, fig. 46-48.

Scalibregma longosetosum Levinsen (1883), p. I35.

Pseudoscalibregma longisetosum Ashworth (Igor), p. 296. 


\begin{abstract}
Matériel ReCueilli :
Lat. N Long. E Profondeur

Station i36. - Mer de Kara, $7 \mathrm{I}^{\circ} \mathrm{OI}^{\prime} \quad 57^{\circ} 57^{\prime} 2 \mathrm{I} 6$ mètres. Filet de fond. Un exemplaire.

L'unique spécimen recueilli, une femelle pleine d'œufs, est bien conforme à la description de ThéEL. Cette espèce ressemble à Scalibregma inflatum, mais elle en diffère par l'absence de branchies et la présence de soies fourchues. Les Eumenia ont quatre à six paires de branchies et une forme bien différente. C'est avec raison qu'AshworTh range cette espèce dans un nouveau genre caractérisé par l'absence de branchies et de cirres anaux. A partir du onzième sétigère les parapodes portent des appendices lamelleux.
\end{abstract}

Famille des Ophéliens Grube

(incl. Polyophthalmiens Quatrefages)

Genre Ammotrypane Rathie

\title{
Ammotrypane cylindricaudatus Hansen (1882).
}

Matériel ReCUeilli :

$$
\text { Lat. N Long. E Profondeur }
$$

Station i53. - Porte de Kara, $70^{\circ} 25^{\prime} \quad 57^{\circ} 56^{\prime} \quad 66$ mètres. Filet de fond, fauberts. Un ex.

Ce spécimen mesure 25 millimètres sur I millimètre. Autant qu'on peut en juger, vu son état de conservation, il a vingt-huit à trente sétigères. La première branchie se montre au deuxième sétigère. Les trois premières paires sont assez développées; les suivantes sont petites et courtes, atteignant, environ, le quart de la longueur des soies. Les cinq dernières paires sont très longues et suivies de quatre sétigères abranches.

Le tube anal est assez allongé et bifide.

Sauf le nombre de sétigères peut-être un peu moins élevé (?), ce spécimen ne présente pas de différences notables avec le type décrit par HANSEN.

\section{Famille des Capitelliens Grube (Halelminthea Carus)}

\section{Genre Notomastus SARS}

\section{Notomastus latericeus Sars.}

Notomastus latericeus SARS (1856), p. 9-12, pl. II, fig. 8-17.

Capitella rubicunda Keferstein (I862), p. I23, pl. XI, fig. 7-18.

Sandanis rubicundus Kinberg (I866), p. 343 .

Notomastus rubicundus EIsIg (1887), p. 863.

Arenia cruenta Quatrefages (1865), p. 250, pl. XI, fig. I6-23. 
Matériel recueilli ': $\begin{array}{lllll}\text { Station I46. - Porte de Kara, } & \text { Lat. N } & \text { Long. E } & \text { Profondeur } & \\ 70^{\prime} & 58^{\circ} 33^{\prime} & \text { I35 mètres. } & \text { Fauberts. Un exemplaire. }\end{array}$

Ce tout jeune spécimen, dont il n'existe plus que la région antérieure, mesure I5 millimètres sur I millimètre. Il est néanmoins reconnaissable à la forme de son lobe céphalique et à la disposition de ses soies thoraciques.

\section{Famille des Maldaniens SavignY}

(Clyméniens Quatrefages)

\section{Genre Maldane Grube}

\section{Maldane Sarsi Malmgren.}

Maldane Sarsi Malmgren (I867), p. 208, pl. XI, fig. 57.

Clymene Koreni Hansen (1882), p. 40.

Maldane Sarsi Arwidsson (igo6), p. 25I, pl. VI, fig. I92-rg9; pl. X, fig. 333-338.

Maldane Sarsi Fauvel (rgog), p. I4, fig. I.

Matériel Recueilli :

Lat. N Long. E Profondeur

Station I54. - Mer Mourmane, $70^{\circ} 19^{\prime} 56^{\circ} 42^{\prime} \quad 98$ mètres. Filet de fond. Un exempl. Station 222. - Océan Glacial, $77^{\circ} 46^{\prime} 64^{\circ} \mathrm{I} 4^{\prime} 290$ mètres. Sondeur Gilson. Un ex. Station 227. - Mer de Barents, $75^{\circ} 09^{\prime} \quad 42^{\circ} 08^{\prime}$ 200 mètres. Sondeur Gilson. Deux ex.

La plupart sont encore renfermés dans leur épais tube vaseux, cylindrique. La région antérieure présente encore une coloration rougeâtre. Le bord ventral du limbe anal est faiblement et irrégulièrement crénelé, comme sur les exemplaires du Spitsbergen et des Açores de la collection du Prince de Monaco que j'ai décrits (Fauvel, igo6, p. I6, fig. $I^{a}$ et $\left.I^{b}\right)$.

\section{Genre Praxillura Verrill}

\section{Praxillura longissima Arwidsson.}

Praxillura longissima Arwidsson (I906), p. 27, pl. I, fig. I; pl. VII, fig. 208, 212, 2I4, 215, 218.

Matériel RECUEILli :

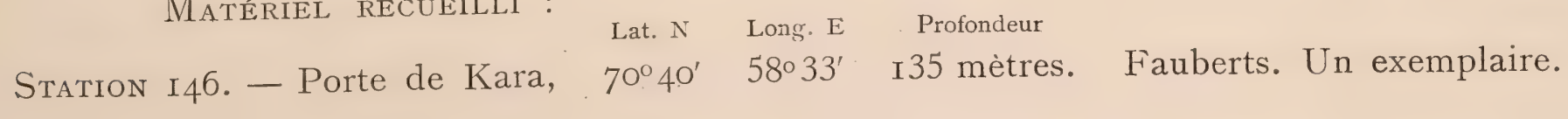


Ce petit spécimen mesure I5 millimètres sur I.6 millimètre. La tête est arrondie. Aux cinq premiers sétigères il n'existe, à la rame ventrale, qu'une ou deux grosses soies aciculaires. Au sixième sétigère apparaissent des uncini rudimentaires, au nombre de trois ou quatre. Ensuite les uncini normaux ont deux ou trois dents au vertex et une barbule sous-rostrale. Les soies dorsales, droites, bi-limbées sont relativement courtes. La même station a fourni aussi quelques fragments d'un gros Maldanien indéterminable.

\section{Famille des Ammochariens MaLmgren}

\section{Genre Owenia Delle Chiaje}

\section{Owenia assimilis Sars.}

Ammochares assimilis SARS (185i), p. 20 I - MALMGREN (I867), p. 2 IO.

Owenia assimilis Levinsen (i 883 ), p. 148.

Matériel Recueilli :

Lat. $\mathrm{N}$ Long. $\mathrm{E} \quad$ Profondeur

Station 222. - Océan Glacial, $77^{\circ} 4^{\prime} \quad 64^{\circ} \mathrm{I} 4^{\prime} \quad 290$ mètres. Sondeur Gilson. Un exempl.

Ce petit spécimen était encore renfermé dans son tube formé de petits grains quartzeux irréguliers qui ne sont pas régulièrement imbriqués comme les débris plats de coquilles qui garnissent le tube de l'Owenia fusiformis.

La région antérieure, bien conservée, correspond bien à la description et aux figures de MaLmgren. Les uncini postérieurs, vus de profil, semblent n'avoir qu'une seule dent, mais en les examinant de face on constate la présence de deux dents parallèles situées à la même hauteur. De Saint-Joseph (I898, p. 4OI) a constaté aussi la présence de deux dents aux crochets de l'Owenia fusiformis vus de face ou de trois quarts. (P1. I, fig. 2I.)

\section{Genre Myriochele Malmgren}

\section{Myriochele Heeri Malmgren.}

Myriochele Heeri Malmgren (I867), p. 2II, pl. VIII, fig. 37.

Myriochele Sarsi Hansen (I882), p. 4I, pl. VI, fig. 6-I 2.

Myriochele Danielseni Hansen (I882), p. 42, pl. VI, fig. i3-i5. 
Matériel Recueilli : $\begin{array}{lcccc} & \text { Lat. N } & \text { Long. E } & \text { Profondeur } & \\ \text { Station 138. - Mer de Kara, } & 70^{\circ} 58^{\prime} & 58^{\circ} 04^{\prime} & \text { 2I } 2 \text { mètres. } & \text { Filet de fond. Un exempl. } \\ \text { Station I46. - Porte de Kara, } & 70^{\circ} 40^{\prime} & 58^{\circ} 33^{\prime} & \text { I35 mètres. } & \text { Fauberts. Un exemplaire. }\end{array}$

Le tube de cette espèce est formé de petits grains de quartz jointifs, non imbriqués. Il est cylindrique et très résistant. Les soies dorsales sont longues et capillaires. Les uncini, très nombreux et très petits, portent au vertex deux dents recourbées, superposées, bien visibles de profil, ce qui les distingue de ceux des Owenia (pl. I, fig. 22). La tête, dépourvue d'appendices, est tout à fait caractéristique.

Famille des Chétoptériens Audouin et Edwards

\section{Genre Spiochætopterus SARS}

\section{Spiochæetoplerus typicus Sars.}

Spiochatopterus typicus Sars Fauna litt. Norveg., p. I, pl. I, fig. 8-2I. Spiochatopterus Madeirensis Langerhans (1879), p. 94, pl. IV, fig. 6.

Matériel Recueilli :

Station 62. - Mer de Kara, $71^{\circ} 49^{\prime} \quad 55^{\circ} 52^{\prime}$ I 23 mètres. Sondeur Gilson. Tubes vides. Station 78. - Mer de Kara, $7 \mathrm{I}^{\circ} 42^{\prime} \quad 56^{\circ} 58^{\prime} \quad 2$ mètres. Fauberts. Tubes vides.

Station i 5. - Mer de Kara, $7 \mathrm{I}^{\mathrm{O}} 26^{\prime} \quad 56^{\circ} 59^{\prime} 200$ mètres. Faub ${ }^{\mathrm{ts}}$. Fragments de tubes. Station i39. - Mer de Kara, $70^{\circ} 54^{\prime} \quad 58^{\circ} 28^{\prime} \quad 200$ mètres. Drague. Tubes vides.

Station i54. - Mer Mourmane, $70^{\circ}$ I $^{\prime}$ 56 $42^{\prime} 98$ mètres. Filet de fond. Quelques ex.

Station i59. - Mer Mourmane, $70^{\circ} 20^{\prime}$ 56 36 90 mèt.(?). Filet de fond. Tubes vides.

Station i6i. - Mer Mourmane, $70^{\circ} 20^{\prime}$ 56 36' 90 mètres. Filet de fond.

Station 222. - Océan Glacial, $77^{\circ} 4^{6^{\prime}} \quad 64^{\circ} \mathrm{I} 4^{\prime} 290$ mètres. Sondeur Gilson.

Fragments de tubes.

Station 227. - Mer de Barents, $75^{\circ} 09^{\prime} \quad 42^{\circ} 08^{\prime} \quad 200$ mètres. Sondeur Gilson. Nomb. ex.

Tous les tubes, sauf quelques-uns des stations 154 et 227, renfermant encore des débris de l'animal, sont vides. Les tubes de la station 227 , très nombreux, atteignent jusqu'à 20 centimètres de long. 


\section{Famille des Ampharétiens MaLmgren}

\section{Genre Amphicteis Grube}

(Grube p. p. Malmgren et von Marenzeller char. emend.)

\section{Amphicteis Sundevalli Malmgren.}

Amphicteis Sundevalli Malmgren (г865), p. 366, pl. XXV, fig. $7^{3}$.

MAtériel RECUEILli :

Lat. $\mathrm{N}$ Long. E Profondeur

Station i6i. - Mer Mourmane, $70^{\circ} 20^{\prime} \quad 56^{\circ} 36^{\prime}$ go mètres. Filet de fond. Un exemplaire.

Ce petit spécimen, encore en partie enveloppé des débris de son mince tube membraneux, mesure 8 millimètres sur r.5 millimètre. Les tentacules sont gros et lisses. Les branchies sont tombées. Le nombre des sétigères thoraciques est de dixsept, suivis de dix-neuf abdominaux, dont le dernier porte deux cirres anaux. Les lobes dorsaux des pieds abdominaux sont très marqués. Les palées sont droites, capillaires, très fines. Les uncini ont cinq dents, plus une petite recourbée en sens inverse. A l'abdomen les uncini, de forme un peu différente, sont épais et portent deux rangées parallèles de quatre ou cinq dents.

\section{Genre Ampharete Malmgren}

\section{Ampharete arctica Malmgren.}

A mpharete arctica Malmgren (I865), p. 364, pl. XXVI, fig. 77.

Amphicteis arctica THÉEL (I879), p. 6r.

Ampharete Lindströmi MALMGREN (I867), p. 2I4.

Matériel Recueilli :

$$
\text { Lat. N Long. E Profondeur }
$$

Station i54. - Mer Mourmane, 70 $19^{\prime}$ ' $56^{\circ} 42^{\prime} \quad 98$ mètres. Filet de fond. Un exempl. Station I59. - Mer Mourmane, $70^{\circ} 20^{\prime}$ 56 36' 90 mètres. Filet de fond. Un exempl. Stration 222. - Océan Glacial, $77^{\circ} 4^{\prime} 6^{\prime} 64^{\circ} 14^{\prime} 290$ mètres. Sondeur Gilson. Deux ex.

Les spécimens de la station 222 sont de grande taille (45 et 50 millimètres). Ils sont accompagnés de leur tube vaseux, épais, entremêlé de débris d'algues. 
Les palées mucronées, brusquement atténuées en pointe filiforme, sont caractéristiques. Comme ThéEl, j'observe, en outre de deux courts cirres anaux, une couronne de petites papilles donnant à l'anus un aspect crénelé.

L'estomac est bien du type Ampharete, sans cæcum interne. Autant que j'ai pu en juger par une dissection sommaire, il existe trois paires de néphridies, dont l'une à long tube, comme la paire antérieure de l'Ampharete Grubei, les deux autres courtes du type Amphicteis. Chez l'Ampharete Grubei, il n'existe qu'une seule paire de ces néphridies à tube court.

Les uncini thoraciques ont deux rangées parallèles de six à huit dents; les uncini abdominaux postérieurs n'ont que cinq dents à chaque rangée.

\section{Ampharete gracilis Malmgren.}

Ampharete gracilis Malmgren (1865), p. 365, pl. XXVI, fig. 75 .

Amphicteis gracilis THÉEL (1879), p. 60.

Anobothrus gracilis Levinsen (1883), p. 165.

$\begin{array}{cccr}\text { Matériel ReCUeilli : } & \text { Lat. N } & \text { Long. E } & \text { Profondeur } \\ \text { Station I } 54 .- \text { Mer Mourmane, } & 70^{\circ} \mathrm{Ig}^{\prime} & 56^{\circ} 42^{\prime} & 9^{8} \text { mètres. Filet de fond. Un exemplaire. }\end{array}$

L'unique spécimen mesure 38 millimètres sur 3 millimètres. Les branchies, très longues, sont détachées; l'une mesure quatre fois la largeur du corps (II à I2 millimètres). Les palées sont très effilées.

Cette espèce, qui diffère de $l^{\prime} A$. arctica par ses longues branchies et la forme de ses palées, se rapproche notablement de l'A. Grubei, et la présence de treize sétigères au lieu de douze à l'abdomen ne me paraît pas un caractère suffisant pour en faire un genre à part.

\section{Genre Samytha Malmgren}

\section{Samytha sexcirrata Sars.}

Sabellides sexcirrata SARS (I856), Faun. Litt. Norv. II, pp. 23-24. Samytha sexcirrata MALMgren (1865), p. 37o, pl. XX, fig. 49.

\section{MatéRIEL Recueilli : $\quad$ Lat. N Long. E Profondeur}

Station 222. - Océan Glacial, $77^{\circ} 4^{\prime} 6^{\prime} \quad 64^{\circ}$ I $4^{\prime} 290$ mètres. Sondeur Gilson. Un exempl.

Ce petit Ampharétien, de I7 millimètres sur I millimètre, était encore renfermé dans son tube membraneux, annelé, recouvert d'une fine couche de vase brune et hérissé de spicules d'éponges. 


\section{Genre Melinna Malmgren}

\section{Melinna cristata Sars.}

Sabellides cristata SARS (1856), pp. I9-24, pl. II, fig. I-7.

Melinna cristata Malmgren (I865), p. 37I, pl. XX, fig. 50.

Matériel RECUeilli :

Lat. N Long. E Profondeur

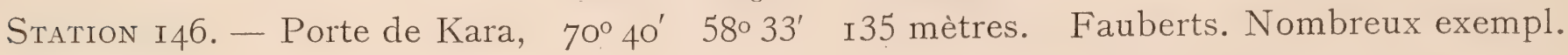

Cette station a fourni une trentaine de spécimens de différentes tailles. Deux étaient encore accompagnés de leur tube membraneux, recouvert de vase, dont l'extrémité antérieure, qui sans doute fait saillie au-dessus du sol, est garnie de petits graviers noirs, fixés par leur pointe et entremêlés de débris de tubes de Spiochatopterus et de fragments d'algues.

Sur quelques spécimens, dont la membrane thoracique est gonflée et boursouflée par le formol, les dents sont peu distinctes.

\section{Famille des Térébelliens GRUBE}

(MalmGRen rev.)

Genre Amphitrite O. F. MÜLLER

(Malmgren, Marenzeller char. emend.)

\section{Amphitrite cirrata Müller.}

Terebella cirrata Montagu (1818), p. 342 , pl. XI, fig. I.

Amphitrite cirrata Malmgren (I865), p. 375, pl. XXI, fig. 53.

MAtériel RECUEILli :

Lat. N Long. E Profondeur

Station i6r. - Mer Mourmane, $70^{\circ} 20^{\prime} 56^{\circ} 36^{\prime}$ go mètres. Filet de fond. Un exempl.

Le tube de cette espèce, formé de vase agglomérée, est épais et cassant.

La teinte du corps, dans l'alcool-formol, est d'un rouge vineux violacé.

Cet individu, unique, paraît entier et mesure 60 millimètres sur 6 millimètres.

Cette espèce arctique descend jusqu'aux Açores et existe aussi dans la Méditerranée. 


\section{Genre Scione Malmaren}

\section{Scione lobata Malmgren.}

Scione lobata Malmgren (i865), p. 383, pl. XXIII, fig. 62 .

Nicolea lobata Marenzeller (I884), p. 166.

Matériel RECUEILli :

Lat. N Long. E Profondeur

Station I53. - Porte de Kara, $70^{\circ} 25^{\prime} \quad 57^{\circ} 56^{\prime} 66$ mètres. Filet de fond, faub. Deux ex. Station I54. - Mer Mourmane, $70^{\circ}$ I $9^{\prime} 56^{\circ} 42^{\prime} 98$ mètres. Filet de fond. Très commun. Station r 59. - Mer Mourmane, $70^{\circ} 20^{\prime}$ 56 36 90 mètres. Filet de fond. Très commun. Station I6I. - Mer Mourmane, $70^{\circ} 20^{\prime}$ 56 36 $6^{\prime}$ go mètres. Filet de fond. Très commun.

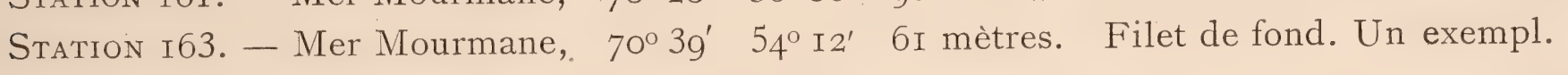

Les stations I54, I59, I6I ont fourni un très grand nombre de spécimens, renfermés dans leurs tubes cylindriques, très tortillés, revêtus de graviers. Ils sont parfois accompagnés de tubes de Thelepus, qui ont un aspect analogue. Les tubes de Scione, plus résistants que ceux de Lanice conchylega, ne sont pas comme ceux-ci terminés par une frange, leur partie libre hors du sable est beaucoup plus longue et très contournée.

\section{Genre Thelepus Malmgren}

\section{Thelepus cincinnatus Fabricius.}

Amphitrite cincinnata FABRIcius (1780), Fauna Groenlandica, p. 286.

Terebella lutea Risso (i826), p. 409.

Thelepus Bergmanni Leuckart (I849), p. I69, fig. 4.

Lumara flava Stimpson (i 853 ), p. 30.

Terebella pustulosa Grube (1860), p. Ioo, pl. IV, fig. 7 .

Venusia punctata Johnston (I865), 24I.

Phenacia terebellö̈des Quatrefages (1865), p. 375.

Heterophenacia micleolata Claparede (1868), p. 13.

Phenacia ambigrada Claparède (1868), p. I42, pl. XVIII, fig. 6.

Phenacia retrograda Claparède (1868), p. $14^{3}$, pl. XVIII, fig. 7 .

Thelepodopsis flava SARS (1871), p. 4I5.

Thelepus circinnata Malmaren (I865), p. 387, pl. XXII, fig. 58.

Thelepus cincinnatus Marenzeller (I884), p. 205, pl. I, fig. 8. 
Matériel Recueilli :

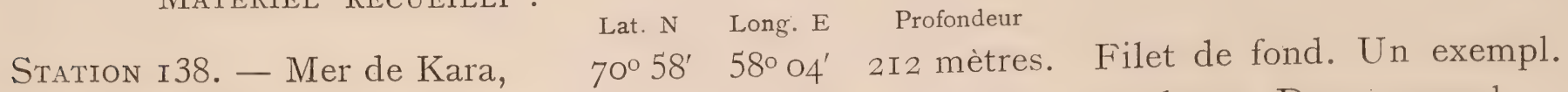
Station I46. - Porte de Kara, $70^{\circ} 40^{\prime} \quad 58^{\circ} 33^{\prime}$ I 35 mètres. Fauberts. Deux exempl. Station I47. - Porte de Kara, $70^{\circ} 39^{\prime} \quad 58^{\circ} 33^{\prime}$ I 27 mètres. Drague, fauberts. Deux ex. Station I49. - Porte de Kara, $70^{\circ} 35^{\prime} \quad 58^{\circ} 22^{\prime} \quad 42-75$ mèt. Fauberts. Deux exempl. Station i53. - Porte de Kara, $70^{\circ} 25^{\prime} \quad 57^{\circ} 56^{\prime} \quad 66$ mètres. Filet de fond, faub. Deux ex. Station I54. - Mer Mourmane, $70^{\circ}$ I $9^{\prime} \quad 56^{\circ} 42^{\prime} \quad 98$ mètres. Filet de fond. Trois exempl. Station I59. - Mer Mourmane, $70^{\circ} 20^{\prime} \quad 56^{\circ} 36^{\prime} 90$ mètres. Filet de fond. Un exempl. Station i6i. - Mer Mourmane, $70^{\circ}$ 20' 56 36' 90 mètres. Filet de fond. Deux exempl.

Cette espèce atteint, dans les régions arctiques, une taille exceptionnelle. Elle paraît y être fort commune, mais elle n'est pas limitée à ces mers, car on la rencontre encore dans la Manche, dans l'Atlantique jusqu'aux Canaries et dans la Méditerranée. Sur les côtes océaniques de la France on la trouve parfois en abondance. Dans certaines parties de la Manche, aux environs de Cherbourg, par exemple, elle paraît manquer et elle est remplacée par le Thelepus setosus, qui s'en distingue par ses trois paires de branchies. Dans la Mer du Nord, les deux espèces coexistent.

\section{Genre Polycirrus Grube}

Polycirrus albicans Malmgren.

Leucariste albicans MALmgren (I865), p. 39o, pl. XXIII, fig. 6I.

1 Matériel Recueilli :

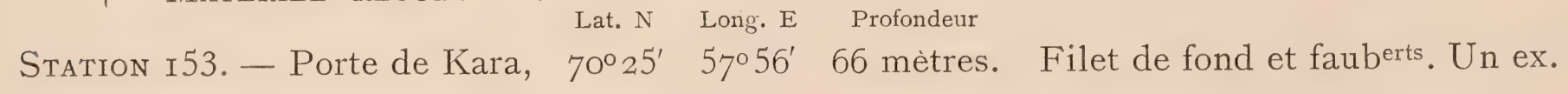

Cette station n'a fourni qu'un seul petit spécimen en assez mauvais état.

Famille des Serpuliens Burm.

(GRUBE char. emend.)

TRIBU DES SABELLIDES

Genre Potamilla Malmgren

\section{Potamilla neglecta Sars.}

Sabella neglecta SARS (I85I), p. 83.

Potamilla neglecta Malmgren (1865), p. 40I, pl. XXVII, fig. 84 . 


\section{Matériel Recueilli :}

\section{Lat. N Long. E Profondeur}

Station i6r. - Mer Mourmane, $70^{\circ} 20^{\prime}$ 56 $36^{\prime}$ go mètres. Filet de fond. Un exempl.

Le tube, formé d'une membrane résistante recouverte de très fins petits graviers, est aplati à l'entrée avec une légère tendance à l'enroulement, comme celui de la $P$. reniformis.

Les soies caractéristiques et l'absence d'yeux branchiaux différencient cette espèce de la $P$. reniformis.

\section{Genre Dasychone SARS}

\section{Dasychone infarcta Kröyer.}

Sabella infarcta Kröyer (1856), p. $2 \mathrm{I}$.

Dasychone decora SARS (1862), p. I24.

Dasychone infarcta Malmgren (1865), p. 403, pl. XXVIII, fig. 86.

\section{Matériel Recueilli :}

Station II5. - Mer de Kara, $71^{\circ} 26^{\prime} \quad 56^{\circ} 59^{\prime} 200$ mètres. Fauberts. Un exemplaire. Station r38. - Mer de Kara, 70 58' 580 04' 2 I2 mètres. Filet de fond. Un exempl. Station I53. - Porte de Kara, $70^{\circ} 25^{\prime} \quad 57^{\circ} 56^{\prime} \quad 66$ mètres. Filet de fond, faub. Un ex.

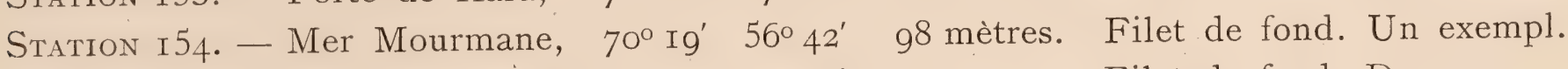
Station I59. - Mer Mourmane, $70^{\circ} 20^{\prime} \quad 56^{\circ} 36^{\prime}$ go mètres. Filet de fond. Deux ex. Station I6I. - Mer Mourmane, $70^{\circ} 20^{\prime}$ 56 36 90 mètres. Filet de fond. Quatre ex.

Plusieurs spécimens sont encore accompagnés de leur tube.

Cette espèce se distingue de la suivante par l'absence d'yeux branchiaux.

\section{Dasychone Bombyx Dalyell.}

Amphitrite Bombyx Dalyell (r853), p. 236.

Branchiomma Dalyelli KöLliker (1858), p. 539 .

Dasychone argus SARS (I862), p. I25.

Sabella polyzonos GrUBe (I863), p. 63, pl. VI, fig. 5 .

Sabella Bombyx Johnston (1865), p. $26 \mathrm{I}$.

Sabella verticillata Quatrefages (I865), p. 440, pl. XX, fig. 3-4.

Dasychone Dalyelli MaLmgren (I867), p. 224.

Dasychone Bombyx Chatin (I878), p. 28, pl. III, fig. 4I-42.

Dasychone pulyzonos Lo Bianco (I 893 ), p. $7^{3}$. 
Matériel recueilli :

Station i54. - Mer Mourmane, $70^{\circ} 19^{\prime} 56^{\circ} 42^{\prime} 98$ mètres. Filet de fond. Un exempl.

Ce petit spécimen, entier, accompagné de son tube, porte quelques paires d'yeux à la base de ses branchies rayées de brun.

Les stations I46 et I6I ont fourni chacune un fragment de Dasychone indéterminable, vu l'absence du panache branchial.

\section{Genre Chone Kröyer}

\section{Chone infundibuliformis Kröyer.}

Chone infundibuliformis Malmgren (1865), p. 404, pl. XXVIII, fig. 87.

Matériel Recueilli :

Station it5. - Mer de Kara, $7 I^{\circ} 26^{\prime} \quad \begin{aligned} & \text { Long. E } \\ & 56^{\circ}\end{aligned}$

Station ilg. - Mer de Kara, $7 \mathrm{I}^{\circ} 20^{\prime} 56^{\circ} 57^{\prime} \mathrm{I} 66$ mètres. Fauberts. Un exemplaire.

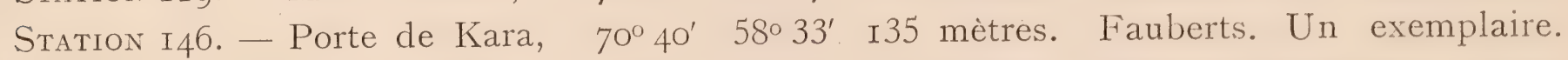

Station I 47. - Porte de Kara, $70^{\circ} 39^{\prime} \quad 58^{\circ} 33^{\prime}$ I 27 mètres. Drague et fauberts. Un ex.

Station I 49. - Porte de Kara, $70^{\circ} 35^{\prime} \quad 58^{\circ} 22^{\prime} \quad 42-75$ mèt. Fauberts. Deux exempl.

Station i53. - Porte de Kara, $70^{\circ} 25^{\prime} 57^{\circ} 56^{\prime} 66$ mètres. Filet de fond, fauberts.

Nombreux exemplaires.

Station I54. - Mer Mourmane, $70^{\circ}$ I9' 56 42' 98 mètres. Filet de fond. Un exempl.

Station i59. - Mer Mourmane, $70^{\circ} 20^{\prime}$ 56 36 90 mètres. Filet de fond. Deux ex.

Station i6r. - Mer Mourmane, $70^{\circ} 20$ 56 36' 90 mètres. Filet de fond. Un exempl.

Les branchies se terminent par une pointe aplatie, foliacée, largement limbée; une palmure très élevée les réunit. Le tube, chitineux, sinueux, transparent est parfois adhérent à de gros tubes de Dasychone infarcta.

\section{Chone Duneri Malmgren.}

Chone Duneri Malmgren (I867), p. 225, pl. XIV, fig. 75.

Chone longicirrata SARS (I87I), p. 4I5.

Matériel RECUeilli :

Lat. $\mathrm{N}$ Long. E Profondeur

Station 222. - Océan Glacial, $77^{\circ} 4^{\prime} 64^{\circ} 14^{\prime} 290$ mètres. Sondeur Gilson. Un exempl. 
Cette espèce se distingue de la précédente par son grand panache de branchies à extrémité en pointe beaucoup plus allongée et par sa collerette inclinée, allongée du côté ventral.

\section{Genre Euchone Malmgren}

\section{Euchone papillosa Sars.}

Sabella papillosa SARS (I851), p. 83.

Chone papillosa SARS (I862), p. I29.

Euchone papillosa MaLmgren (i865), p. 407, pl. XXIX, fig. 94.

Chone flabelligera KRöYER (I856), p. 34.

Euchone tuberculosa Kr., Malmgren (I865), p. 407, pl. XXIX, fig. 92.

\section{Matériel Recueilli :}

$$
\text { Lat. N Long. E Profondeur }
$$

Station i6I. - Mer Mourmane, $70^{\circ} 20^{\prime} \quad 56^{\circ} 36^{\prime}$ go mètres. Filet de fond. Un exempl.

L'unique spécimen mesure 60 millimètres de long avec les branchies qui atteignent I6 millimètres. Il est renfermé dans un long tube mince analogue à celui de Sabella pavonina.

Les segments du milieu du corps sont bien plus longs que larges.

\section{Euchone analis Kröyer.}

Sabella analis KRÖYER (I856), p. 17.

Euchone analis Malmgren (I865), p. 406, pl. XXVIII, fig. 88.

Matériel Recueilli :

$$
\text { Lat. } \mathrm{N} \text { Long. } \mathrm{E} \quad \text { Profondeur }
$$

Station i53. - Porte de Kara, $70^{\circ} 25^{\prime} \quad 57^{\circ} 56^{\prime} 66$ mètres. Filet de fond, faubss. Un ex. Station i59. - Mer Mourmane, $70^{\circ} 20^{\prime}$ 56 36 90 mètres. Filet de fond. Un exempl.

Les deux spécimens ont perdu leurs branchies. Le corps, assez court, porte des boucliers ventraux rectangulaires se touchant. Les soies dorsales sont de deux sortes : capillaires et spatulées. La dépression anale, caractéristique du genre, est bien élargie mais le bord n'en est pas ondulé. 


\section{TRIBU DES SERPULIDES}

\section{Genre Apomatus Philippi, Mörch \\ (de Satnt-Joseph rev.)}

Apomatus similis Marion et Bobretsky.

A pomatus similis Marion et Bobretsky (1875), p. 97, pl. XII, fig. 25 .

A pomatus similis Marion (1878), p. 29, pl. XVII, fig. 9.

Apomatus similis Marenzeller (I893), p. I5, pl. III, fig. I2.

Apomatus similis de SAInT-Joseph (1894), p. 36g, pl. XIII, fig. 4I5-4Ig.

A pomatus similis Fauvel (1909), p. 73 et (1910) p. 695.

Apomatus globifer ThÉEL (I879), p. 66, pl. IV, fig. 63-65.

Apomatus globifer Marenzeller (i893), p. i4, pl. III, fig. il.

\section{Matériel Recueilli :}

Lat. $\mathrm{N}$ Long. E Profondeur

Station 78. - Mer de Kara, $7 \mathrm{I}^{\circ} 42^{\prime} \quad 56^{\circ} 58^{\prime} 2$ mètres. Fauberts. Un ex. et tubes vides.

Station ilo. - Mer de Kara, $7 \mathrm{I}^{\circ} 3 \mathrm{I}^{\prime}, 57^{\circ} 09^{\prime} 220$ mètres. Fauberts. Tubes vides.

Station ili. - Mer de Kara, $7 \mathrm{I}^{\circ} 3 \mathrm{I}^{\prime} 57^{\circ} 08220$ mètres. Fauberts. Un exemplaire.

Station ii5. - Mer de Kara, 7 I $^{\circ} 26^{\prime} \quad 56^{\circ} 59^{\prime} 200$ mètres. Fauberts. Un exemplaire.

Station ilg. - Mer de Kara, 7 I $^{\circ} 22^{\prime} \quad 56^{\circ} 57^{\prime}$ i66 mètres. Fauberts. Deux exemplaires.

Station i2o. - Mer de Kara, 7 I $^{\circ} 2 I^{\prime} 56^{\circ} 57^{\prime}$ I65 mètres. Fauberts. Deux exemplaires et un tube vide.

Station i26. - Mer de Kara, $7 \mathrm{I}^{\circ}$ I8 $57^{\circ}$ o $3^{\prime}$ I 72 mètres. Fauberts. Un exemplaire.

Comme je l'ai déjà montré antérieurement (Igog, p. 73), aucun caractère ne permet de séparer l'Apomatus globifer des mers boréales de l'Apomatus similis de la Manche et de la Méditerranée.

D'après Marenzeller les soies caractéristiques d'Apomatus apparaissent au troisième sétigère chez $l^{\prime} A$. similis et au quatrième seulement chez l'A. globifer. Or, aussi bien sur des exemplaires du Spitsbergen, provenant de la collection du Prince de Monaco, que sur les spécimens ci-dessus de la station I 26 je constate la présence de ces soies spéciales dès le troisième sétigère.

La présence ou l'absence d'yeux branchiaux n'ont également rien de caractéristique, ces organes pouvant exister ou faire défaut chez les deux formes.

En général, les yeux existent chez les jeunes individus et semblent disparaitre avec l'âge comme c'est le cas, d'ailleurs, chez beaucoup d'annélides. 


\section{Genre Chitinopoma Levinsen}

\section{Chitinopoma Fabricii Levinsen.}

Serpula triquetra FABRicius (I780), Fauna Groenlandica, p. 379.

Chitinopoma Fabricii Levinsen (i883), p. 206, pl. II, fig. 4-8; pl. III, fig. 20.

Matériel Recueilli :

$$
\text { Lat. N Long. E Profondeur }
$$

Station r53. - Porte de Kara, $70^{\circ} 25^{\prime} \quad 57^{\circ} 56^{\prime} 66$ mètres. Filet de fond et fauberts.

Un exemplaire.

L'unique spécimen est fixé sur un fragment de test de Balane. Le tube calcaire, subtriangulaire, plus ou moins plissé porte une carène dorsale. L'opercule, chitineux, caractéristique, correspond bien à la figure 4 de Levinsen. Il existe une longue collerette fendue mais la membrane thoracique fait défaut. Aux segments thoraciques les soies sont de deux sortes : $I^{0}$ capillaires effilées, un peu arquées; $2^{\circ}$ soies de Salmacine à aileron crénelé. Les uncini ont des dents nombreuses dont la dernière est plus grosse que les autres. 



\section{INDEX BIBLIOGRAPHIQUE}

Ig06. Arwidsson, Studien über die skandinavischen und arktischen Maldaniden. Zool. Jahrb., Bd XXV.

Igor. Ashworth, The anatomy of Scalibregma inflatum Rathke. Quart. Journ. of Micr. Sc. N. S., vol. XLV, pp. $237-309$.

1834. Audouin et Milne-Edwards, Recherches pour servir à l'histoire du littoral de la France (Annélides). Paris, 1834 .

1878. Chatin, J., Recherches pour servir à l'histoire du bâtonnet optique chez les Crustacés et les Vers. Ann. Sc. Nat. Zool., 6e sér., t. VII.

I863. Claparìde, E., Beobachtungen über Anatomie und Entwicklungsgeschichte wirbelloser. Thiere. Leipzig, I863.

1864. Claparède, E., Glanures zootomiques parmi les Annélides de Port-Vendres. Mém. Soc. Phys. et Hist. Nat. de Genève, t. XVII.

i 868-i 870. Claparìde, E., Les Annélides Chætopodes du golfe de Naples. Mém. Soc. Phys. et Hist. Nat. de Genève, t. XIX et XX.

1853. Dalyeli, The Powers of the Creator.

I839. Dujardin, Observations sur quelques Annélides marines. An. Sc. Nat. Zool., 2 e sér. t. XI.

I864-1868. Ehlers, E., Die Borstenwürmer. Annelida Chætopoda. Leipzig, I864-i868.

I87i. Ehlers, E., Ueber die auf der von Heuglin Waldburgschen Expedition nach Spitzbergen gesammelten Würmer. Sitz̧b. der Phys.-med. Soc. zu Erlangen, III.

1873. Ehlers, E., Zur Kenntniss der Fauna von Nowaya Semlja. Sitzb. der Phys.-med. Soc. zu Erlangen, V. 1874. Ehlers, E., Beiträge zur Verticalbreitung der. Börstenwürmer im Meere. Zeitsch. für wiss Zool., Bd XXIV.

I887. Eisig, H., Die Capitelliden des Golfes von Neapel. Fauna und Flora der Golfes von Neapel., Bd XVI. I780. Fabricius, Fauna Groenlandica.

I908. Fauvel, Pierre, Variation sabelliforme du Spirographis Spallanzanii Viv. à Saint-Vaast-la-Hougue. Bull. Mus. Hist. Nat. de Paris, no 7, rgo8.

1909. Fauvel, Pierre, Deuxième note préliminaire sur les Polychètes provenant des campagnes de l'Hirondelle et de la Princesse-Alice. Bull. Inst. Océanogr. de Monaco, no 142.

1910. Fauvel, Pierre, Sur quelques Serpuliens de la Manche et de la Méditerranée. C. R. A. F. A. S. Congrès de Lille, Igog, pp. 69I-698.

IgII ${ }^{a}$. Fauvel, Pierre, Troisième note préliminaire sur les Polychètes provenant des campagnes de l'Hirondelle et de la Princesse-Alice. Bull. Inst. Océanogr. de Monaco, nº I94. 
igi i ${ }^{b}$. Fauvel, Pierre, Annélides Polychètes du Golfe Persique. Arch. de Zool. Expér. et gén., 6e sér., t. VI. 1866. GreEFF, Ueber die Anneliden Gattung Sphaerodorum (Ersted) und einen neuen Repräsentaten denselben Sphoer. Claparedii. Arch. für Naturgesch., 32 Jahr., Bd I.

1840. Grube, E., Actinien, Echinodermen und Würmer des Mittelmeeres. Konigsberg, I840.

1851. Grube, E., Die Familien der Anneliden mit Angabe ihrer Gattungen und Arten. Arch. fiur Naturgesch., I850-I85I.

1860-1863. Grube. E., Beschreibung neuer oder wenig bekannter Anneliden. 5e Beitrag. Arch. für Naturgesch., I860-1 863.

1882. Hansen, A. G., Den Norske Nordhavs-Expedition I876-I878, VII Zoologi. Annelida. Christiania, I882. 1880. Horst, R., Bijdrage tot de Kennis der Anneliden van onze Kust. Tijdsschr. Nederl. Dierkdg. Vereen., D.-S.

Igor. Johnson, P., The Polychaeta of the Puget Sound region. Proceed. Boston Soc. Nat. Hist., vol. XXIX, $\mathrm{n}^{\circ} \mathrm{i} 8$.

1865. Johnston, Catalogue of the British non parasitical worms. London, 1865

I862. Keferstein, Untersuchungen über niedere Seethiere. Zeitschr. für wiss, Zoologie, Bd XII, Hft. I. 1864-1866. Kinberg, Annulata nova. Efver. of K. Vet. Akad. Förh., I864-I865-I866.

1858. Kölliker, Ueber Kopfkiemer mit Augen an den Kiemen. Zeitschr. fiur wiss. Zoologie, t. IX.

1856. Kröyer, Bidrag til Kundskaben om Sabellerne. Oversigt over Kgl. Danske Vid. Selsk Forh., I856. I879-I884. Langerhans, Die Wurmfauna von Madeira. Zeitschr. für wiss. Zool., Bd XXXII, XXXIII, XXXIX, XL.

1883. Levinsen, Systematisk-geographisk oversigt over de Nordiske Annulata, Gephyrea, Choetognatha og Balanoglossi. Aftr. af Vid. Meddel. fra den naturh. Foren Copenhague, I882-I883.

1846. Levinsen, Kara-Havet Ledorme. Annulata. Dijmphna-Togtets Zool.-Bot. Udbytte, pp. 28g-3o3.

1893. Lo Bianco, S., Gli anellidi tubicoli trovati nel Golfo di Napoli. Atti R. Acad. Sc. Fis. Mat. Napoli (2), vol. $\mathrm{V}, \mathrm{n}^{\circ}$ iा.

I878. Mc'Intosh, W. C., On the Annelida obtained during the Cruise of H. M. S. Valorous to Davis Straits in 1875. Trans. Linn. Soc. London, ser. 2, vol. I.

1879. Mc'Intosh, W. C., On the Annelids of the British polar expedition. Journ. of Linn. Soc. London, vol. XIV.

i886. Mc'Intosh, W. C., Report on the Annelida Polychaeta collected by H. M. S. Challenger. Challenger reports, vol. XII.

Igoo. Mc'Intosh, W. C., A Monograph of the British Annelids, part II. London Ray Society, Igoo. igo8a. Mc'Intosh, W. C., The British Annelids, vol. II, part I, Polychaeta. London Ray Society, I908.

Igo8 ${ }^{b}$. Mc'Intosh, W. C., On the British Sphaerodoridae, Chlorhaemidae and Chaetopteridae. Ann. and Mag. of Nat. Hist., ser. 8́, vol. II, décembre igo8.

1874. Malm, Amulater i havfet utmed Sverges vestkyst och omkring Göteborg. Göteborg Kgl. Vetensk. Handl. Ny. Tidsföljd., I874.

1865. Malmaren, A. J., Nordiska Hafs Annulata. Ofv. af $\mathrm{Kgl}$. Vet. Akad. Förhd. Stockholm.

I867. Malmgren, A. J., Annulata Polychœta Spetsbergiæ, Gronlandix, Islandiæ et Scandinaviæ hactenus cognita. Ofy. af Kgl. Vet. Akad. Förhd. Stockholm.

1877. Marenzeller, E. von, Die Cœlenteraten, Echinodermen und Würmer der K. K. ÖsterreichischUngarischen Nordpolexpedition. Denkschrif. der Math. Nat. Classe der K. Akad. der Wiss. Vienne, Bd XXXV.

i884. Marenzèller, E. vion, Zur Kenntniss der Adriatischen Anneliden. IIIe partie. Sitzb. der K. Akad. der Wiss. Wien Math. naturn. Classe, Bd LXXXIX, 1884. 
I886. Marenzeller, E. von, Poriferen, Anthozoen, Ctenophoren und Würmer von Jan Mayen. Vienne Geroldssohn, I886.

I8go. Marenzeller, E. von, Annulaten des Beringsmeeres. An. K. K. naturhist. Hofmuseum, Bd V.

1892. Marenzeller, E. von, Zoologische Ergebnisse der im Jahre I889 auf kosten der Bremer GeographGeself. von Dr Willy Kückenthal und D. Alf. Walter ausgefuhrten Expedition nach Ost-Spitzbergen. Zool. Jahr., Bd VI.

I893-igo2. Marenzeller, E. von, Polychaeten des Grundes gesammelt. Denkschr. K. Akad. der Wiss. Wien Math. Nat. Classe, Bd LX et LXXIV.

1875. Marion et Bobretzky, Étude des Annélides du Golfe de Marseille. An. Sc. Nat. Zool., 6e sér., t. II.

I878. Marion, Dragages au large de Marseille. An. Sc. Nat. Zool., 6e sér, t. VIII.

i8g6. Mesnil, F., Études de Morphologie externe chez les Annélides. (Spionidiens). Bull. Scient. de France et de Belgique, t. XXIX.

i897. Michaelsen, W., Die Polychaeten Fauna der deutschen Meere. Wiss Meeresuntersuch. deutsche Meere, N. F., Bd II, Heft. I.

igi i. Michel, Autotomie et régénération du çorps et des élytres chez les Polynoidiens. C. R. Acad. des Sc. de Paris, t. CLII.

1874. MöвiUs, Mollusken, Würmer, Echinodermen und Coelenteraten. Die zueite deutsche Nordpolarfahrt in den Jahren I869-1870, II. Leipzig, I874.

I8I8. Montagu, Descriptions of five British species of the genus Terebella of Linné. Transac. Lin. Soc. London, vol. XII.

Igog. Moore, P., The Polychaetous Annelids dredged by the U. S. S. Albatross of the coast of Southern California in Igo4. Proceed. Acad. of Nat. Sc. Philadelphia, June rgog.

1855. Müller, Max, Ueber Sacconereis Helgolandica. Müllers Archiv. für Anat., I855.

I776. MÜller, O. F., Zoologiæ Danicæ Prodromus.

I777-I780. MüLler, O. F., Zoologiæ Danicæ, seu Animalium Daniæ et Norvegiæ rarior. ac minus notorum icones.

I779-I806. Müller, O. F., Zoologia Danica seu Animalium Daniæ et Norvegiæ rarior. ac minus notor. descriptions et historia; ad formam tabularum denuo edid. frater auctoris., IV vol., I40 pl.

184 $3^{a}$. Ersted, Groenlands Annulata dorsibranchiata. K. Danske Selsk. natur. afh., I843.

I84 $3^{b}$. CErsted, Amulatorum Danicorum conspectus. Fas. I. Maricolæ. Copenhague, I 843.

1844. ERsted, Dyr ved Dröbak. Nat. Tijdsskr. Ny. Røkke, I.

r897. Perrier, Ed., Traité de zoologie. Masson, Paris, i897.

1865. Quatrefages, A. De, Histoire naturelle des Annelés marins et d'eau douce. - Annélides et Géphyriens. Roret, Paris, I865.

1843. Rathke, Beiträge zur Fauna Norwegens. Nova acta Acad. Leop. Car. Nat. Cur., vol. XX.

1826. Risso, Histoire naturelle des principales productions méridionales. Paris, i 826.

i887-1888 Saint-Joseph, baron DE, Les Annélides Polychètes des côtes de Dinard. An. Sc. Nat. Zool., I894-1895 $7^{\text {e }}$ sér., t. I, V, XVII et XX.

1898. Saint-Joseph, baron De, Annélides Polychètes des côtes de France (Manche et Océan). An. Sc. Nat. Zool., $8^{e}$ sér., t. V.

igo6. Saint-Joseph, baron DE, Les Annélides Polychètes des côtes de France (Océan et côtes de Provence). An. Sc. Nat, Zool., ge sér., t. III.

I835. SARS, M., Beskrivelser og Jagttagelser over nye eller merkelige $\mathrm{i}$ havet ved den Bergenske Kyst levende dyr.

I 846 -1 856 . Sars, M., Fauna littoralis Norvegiæ. 
I85I. SARS, M., Beretning om en i sommeren i849, foretagen zoologisk reise i Lofoten og Finmarken. Nyt. Mag. f. Nat., vol. VI.

1800. SARS, M., Om de ved Norges kyster forekommende Arter af Annelideslaegten Polynoe Uddrag af en Afhandling. Fohr. Vidensk. Selsk. Christiania, I860.

I862. SARS, M., Om de ved Norges kyster forekommende Arter af den Linnéiske Annelideslaegt Sabella. Christ. Vid. Selsk Forh., I861.

I87I. SARs, G. O., Diagnoser af nye Annelider fra Christianiafjorden efter Prof. M. Sars's efterladte Manuscripter. Fohr Vidensk. Selsk. Christiania, I871.

I853. Strmpson, Synopsis of the Marine invertebrata of Grand Manan. Smith. Contributions to Knowledge, Washington.

1878. Théé, Annélides Polychètes des Mers de la Nouvelle-Zemble. Kgl. Svensk. Vet. Akad. Handl. Ny Följd., vol. XVI, I878.

I887. Webster et Benedict. The Annelida Chaetopoda of Eastport (Maine). U. S. Commission of Fish and Fisheries, pars XIII, for I885. Washington, I887.

1885. Wiren, A., Chaetopoder från Sibiriska Ishafvet och Berings Haf insamlade under Vega-Expeditionen I878-1879. Vega-exped. Vetenskapl. Arbeten, Bd II. 



\section{EXPLICATION DE LA PLANCHE}

Fig. I et 2. Nereis zonata Mgr., de taille moyenne, station I34, serpes homogomphes dorsales. Gr. : 500.

- 3. Nereis zonata Mgr., serpe homogomphe dorsale dun jeune exemplaire de 25 millimètres, station I5 g. Gr. : 500 .

- 4. Nereis zonata Mgr., de taille moyenne, station 134, septième sétigère. Gr. : 40.

- 5. Nereis zonata Mgr., épitoke of de grande taille, parapode de la région moyenne. Gr. : I2.

- 6. Eteone depressa Mgr., parapode. Gr. : I3o.

- 7. Ephesia gracilis Rathke, parapode. Gr. : 13o.

- 8 et 9. Ephesia gracilis Rathke, soies. Gr. : 500.

- 10 à I4. Ephesia peripatus. Clap., différents aspects des soies composées, de face et de profil. Gr. : 500.

- I5. Ephesia peripatus Clap., parapode. Gr. : г30.

- i6. Spharodorum Philippi n. spec., soie composée. Gr. : 500.

- 17. Spharodorum Philippi n. spec. Gr. : 50.

- i8. Spharodorum Philippi n. spec., parapode vu d'en dessus. Gr. : 200.

- i9. Spharodorum Philippi n. spec., parapode vu d'en dessous. Gr. : 200.

- 20. Spharodorum Philippi n. spec., derniers segments et pygidium vus d'en dessus. Gr. : I3o.

-21. Omenia assimilis Sars, uncini de face et de profil. Gr. : 800.

- 22. Myriochele Heeri Mgr., uncini de profil. Gr. : 800 . 
DEC 1) ORI EANS. Campagne arctique de 1907.

[1. I
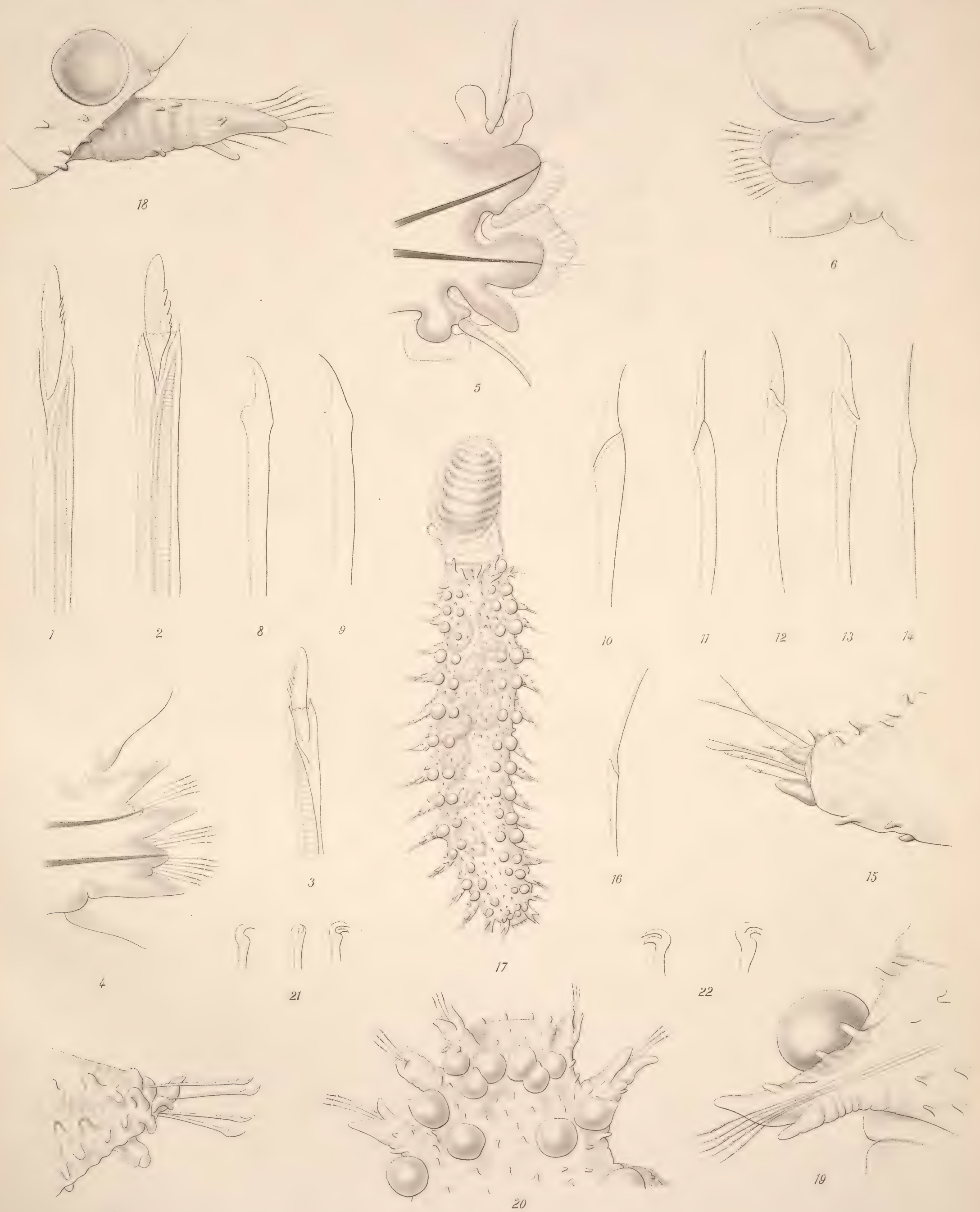



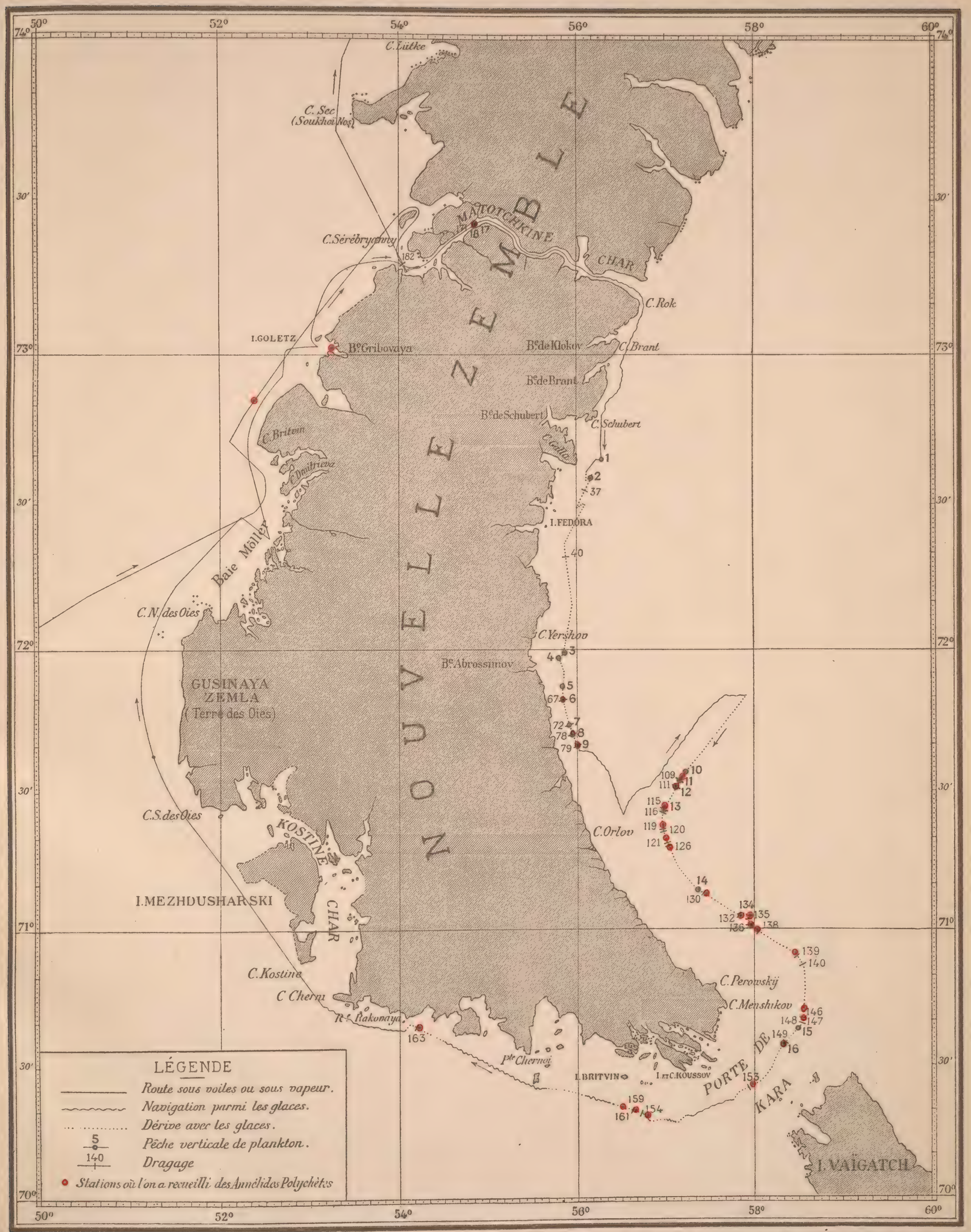

Itinératre DE I.A BELGICA AUTUUR DE L'ILe SUd DE LA Nouvelle-Zemble.

Carte dressée par le Commandant A. de Grimlache. 








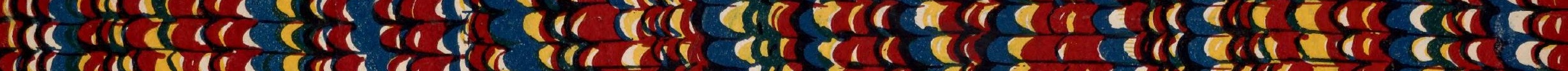

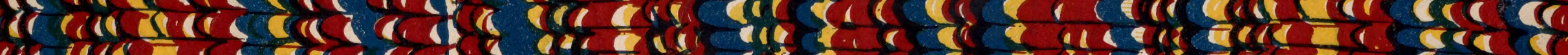

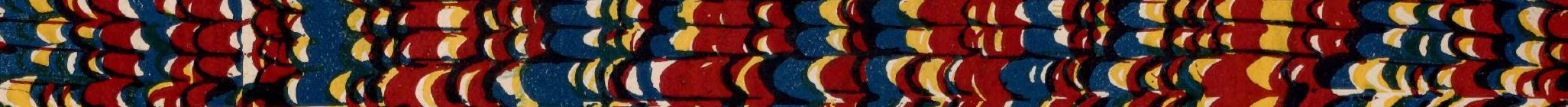

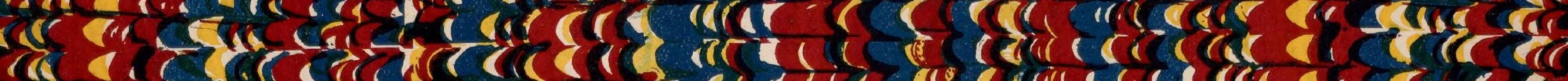

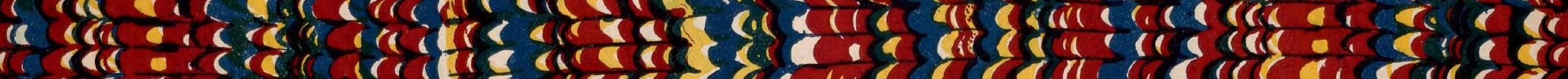

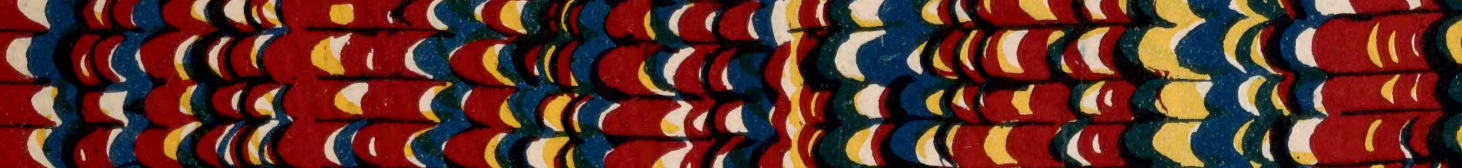

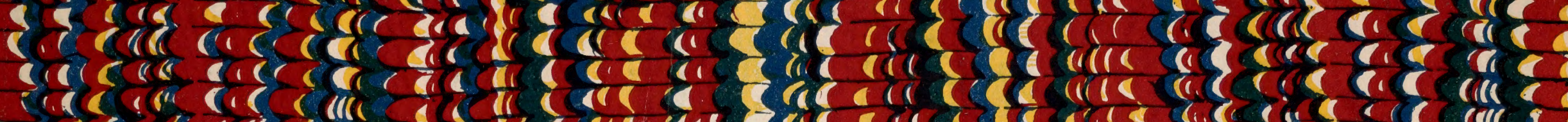

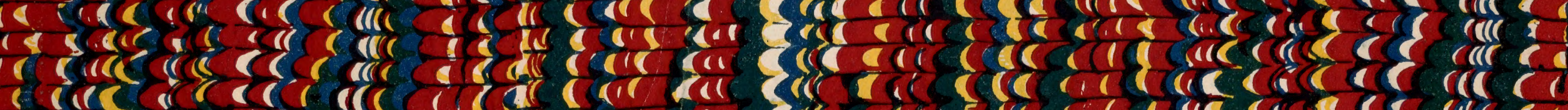

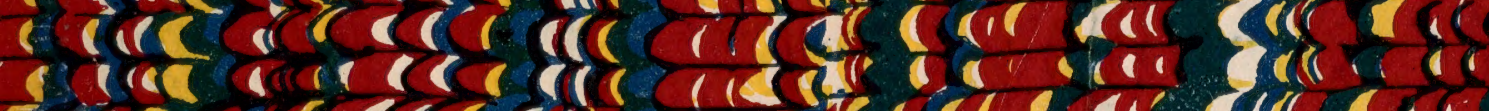

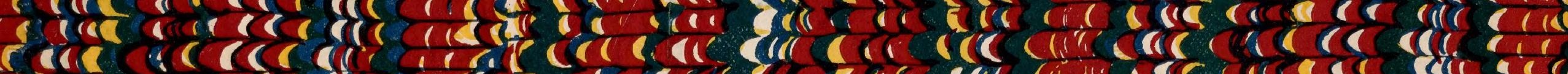

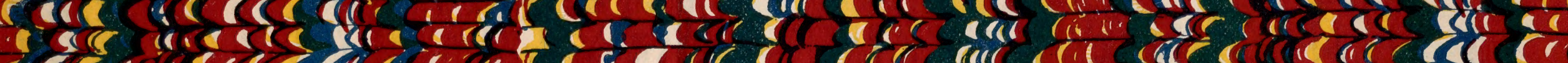

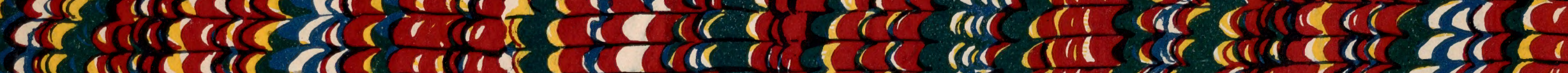

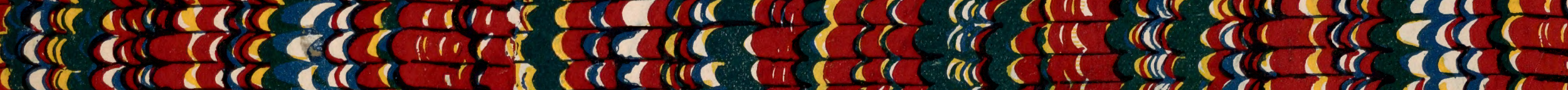

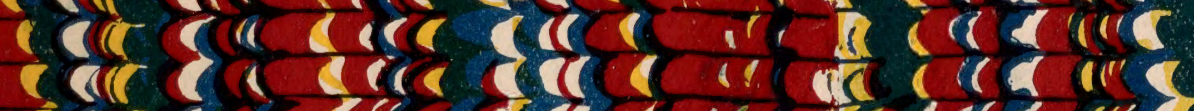

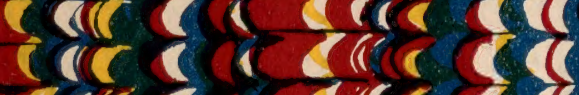

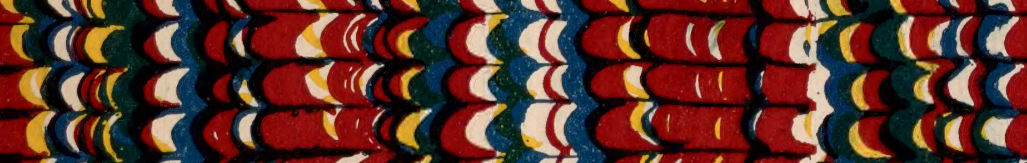

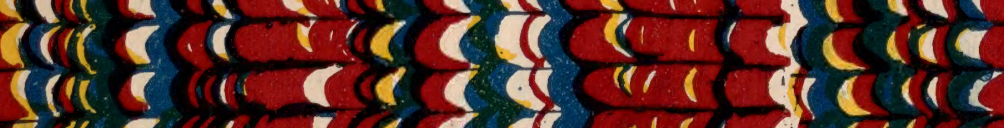
acs

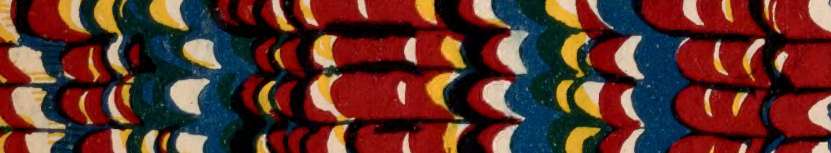

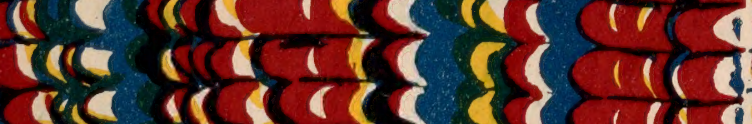

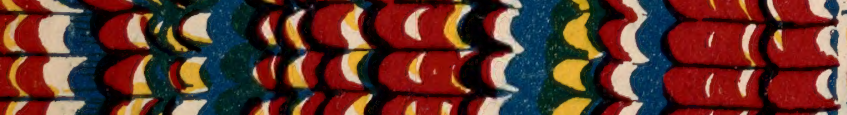
तो दो दोध

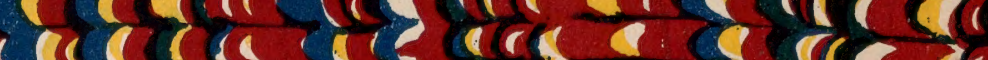



